\title{
The complex regulation of NIS expression and activity in thyroid and extrathyroidal tissues
}

\author{
Garcilaso Riesco-Eizaguirre1,2,3,4, Pilar Santisteban1,4 and Antonio De la Vieja4,5 \\ 'Instituto de Investigaciones Biomédicas 'Alberto Sols', Consejo Superior de Investigaciones Científicas, Universidad Autónoma de Madrid, Madrid, Spain \\ 2Department of Endocrinology and Nutrition, Hospital Universitario de Móstoles, Madrid, Spain \\ ${ }^{3}$ Molecular Endocrinology Group, Faculty of Medicine, Universidad Francisco de Vitoria, Madrid, Spain \\ ${ }^{4}$ Centro de Investigaciones Biomédicas en Red, CIBERONC, Instituto de Salud Carlos III, Madrid, Spain \\ 5Endocrine Tumors Unit, Unidad Funcional de Investigación en Enfermedades Crónicas (UFIEC), Instituto de Salud Carlos III, Madrid, Spain
}

Correspondence should be addressed to G Riesco-Eizaguirre or A De la Vieja: griesco@iib.uam.es or adelavieja@isciii.es

This paper is part of a thematic review section celebrating 80 Years of the Use of Radioiodine. The guest editor for this section was Christopher John McCabe.

\begin{abstract}
The sodium/iodide symporter (NIS) is an intrinsic plasma membrane protein that mediates active iodide transport into the thyroid gland and into several extrathyroidal tissues. NIS-mediated iodide uptake plays a pivotal role in the biosynthesis of thyroid hormones, of which iodide is an essential constituent. For 80 years, radioiodide has been used for the diagnosis and treatment of thyroid cancer, a successful theranostic agent that is extending its use to extrathyroidal malignancies. The purpose of this review is to focus on the most recent findings regarding the mechanisms that regulate NIS both in thyroid and extra-thyroidal tissues. Among other issues, we discuss the different transcriptional regulatory elements that govern NIS transcription in different tissues, the epigenetic modifications that regulate its expression, and the role that miRNAs play in fine-tuning NIS after being transcribed. A review on how hormones, cytokines, and iodide itself regulate NIS is provided. We also review the present stage of understanding NIS dysregulation in cancer, occupied mainly by convergent signaling pathways and by new insights in the route that NIS follows through different subcellular compartments to the plasma membrane. Furthermore, we cover NIS distribution and function in the increasing number of extrathyroidal tissues that express the symporter, as well as the role that NIS plays in tumor progression independently of its transport activity.
\end{abstract}

\author{
Key Words \\ - sodium/iodide symporter \\ (NIS) \\ - gene regulation \\ - thyroid \\ - iodide \\ - extrathyroidal tissues
}

\section{Introduction}

The year 2021 is the 80th anniversary of the first use of radioiodide treatment. On March 31, 1941, Saul Hertz administered radioiodide (131) to treat a woman with hyperthyroidism (Graves' disease) (Hertz et al. 1942, Hertz 2019). A few years later, the first clinical trial leading to a series of 29 patients successfully treated with ${ }^{131}$ I was published (Hertz \& Roberts 1946). Hertz further declared: 'My new research is in cancer of the thyroid which I believe holds the key to the larger problem of cancer in general' (c) 2021 Society for Endocrinology Published by Bioscientifica Ltd. Printed in Great Britain
(Hertz 2019). Evidence of such prediction finally arose in the 1980s, when Mazzaferri and cols published a large retrospective series showing the effectiveness of radioiodide as an adjuvant treatment for patients with differentiated thyroid cancer (Mazzaferri \& Young 1981). In a time where cancer caused devastating effects, as no effective treatments were available, the success of radioiodide treatment was extraordinary and, not surprisingly, it is still considered one of the best and longest molecularly targeted and 
imaging-based treatments ever devised for cancer (De la Vieja \& Riesco-Eizaguirre 2021).

Not until 1996, the molecule responsible for iodide uptake was finally cloned and characterized (Dai et al. 1996). Nancy Carrasco's group demonstrated that a sodium/iodide symporter (NIS) actively transports two ions of sodium along with one of iodide into the cells using the favorable gradient of $\mathrm{Na}^{+}$. NIS is localized in the basolateral membrane of the thyroid follicular cell and represents the first step in thyroid hormone (TH) synthesis (Portulano et al. 2014). Once iodide is transported from the circulation into the cytosol, iodide is then further transported through the apical membrane by pendrin and other proteins into the colloid (De la Vieja \& Santisteban 2018). Iodide is then oxidized by thyroid peroxidase (TPO) using $\mathrm{H}_{2} \mathrm{O}_{2}$ provided by dual oxidase (DUOX2), both enzymes localized at the interphase between the colloid and the apical membrane. TPO also incorporates iodide to the tyrosyl residues of the thyroglobulin (TG) and then couples two iodinated tyrosyl residues to form tri-iodothyronine (T3) and thyroxine (T4), which are stored in the colloid covalently linked to TG in a process called organification. This iodide organification process, involving NIS, TPO, DUOX, and TG, enhances the iodide retention time in the thyroid gland and is, therefore, able to increase the therapeutic efficacy of radioiodide that enters thyroid follicular cells via NIS. Finally, TG, stored in large amounts in the colloid, is taken into the cell through endocytosis and then broken down by lysosomes, releasing T3 and T4, which are then transported to the circulation mainly through MTC8; the remaining iodide that was not used in the production of TH is recycled by the iodotyrosine dehalogenase (DEHAL1).

The experimentally tested secondary structure model for NIS shows a hydrophobic protein with 13 transmembrane segments, an extracellular amino terminus and an intracellular carboxy terminus (Levy et al. 1998, Ravera et al. 2017). There are three sites of glycosylation in the mature form of NIS, and the major phosphorylation region is the $\mathrm{COOH}$ terminus. NIS dimerizes and needs to be located at the basolateral membrane in order to be functional (Huc-Brandt et al. 2011). The human NIS gene is localized on chromosome 19p12-13.2 and encodes a glycoprotein of 643 amino acids (aa) with a molecular mass of approximately $90-100 \mathrm{kDa}$ that can vary between tissues (De la Vieja \& Santisteban 2018). The gene comprises 15 exons interrupted by 14 introns and has an open reading frame of 1929 nucleotides. NIS is a member of solute carrier family $5 \mathrm{~A}$ and has been designed as $S L C 5 A 5$ by the Gene Nomenclature Committee, according to the Human Genome Organization.

C) 2021 Society for Endocrinology Published by Bioscientifica Ltd. Printed in Great Britain
NIS research has become an evolving field of considerable scope. It ranges over the structure/function properties of plasma membrane transporters, gene therapy, thyroid pathophysiology, theranosis of several types of cancer (thyroid, breast, ovary, etc.), and even environmental pollutants and public health, among others. Therefore, discoveries in this field have had a remarkable impact on numerous basic and translational areas, with important clinical implications. The purpose of this review is to focus on the most recent findings regarding the mechanisms that regulate NIS, both in thyroid and extra-thyroid tissues. In the past 2 decades, the mechanisms governing NIS function and expression have turned out to be increasingly complex. The more mechanistic information we have, however, the better equipped we are to extend the clinical applications for this molecule.

\section{Promoters and enhancers regulating NIS transcription}

Transcriptional regulatory elements in complex genomes are key players in the dynamic transcription of genes during development, tissue homeostasis, and disease (Schaffner 2015, Andersson \& Sandelin 2020). Identifying the promoters and enhancers driving important biological processes can be challenging and has been relatively unexplored in thyroid pathophysiology on a genome-wide scale. Given the importance of NIS in iodide metabolism and given its functional expression in several tissues, it is to be expected that NIS transcription is under the control of several promoters and enhancers to regulate temporal and spatial expression in tissues. Substantial progress has been made in two tissue-specific contexts, the thyroid and mammary gland (Fig. 1).

\section{In the thyroid}

It is well established that specific gene transcription in the thyroid is orchestrated by the joint expression of three transcription factors: NKX2.1 (previously known as TTF1), a homeodomain-containing protein; FOXE1 (previously known as TTF2), a forkhead protein; PAX8, a paired domain-containing protein (De Felice \& Di Lauro 2004) (Fig. 1 left panel). Initially, a proximal rat NIS promoter to which NKX2.1 binds to was identified, conferring a thyroid-specific transcription (Endo et al. 1997). A thyroidstimulating hormone (TSH)-responsive element (TRE) and 


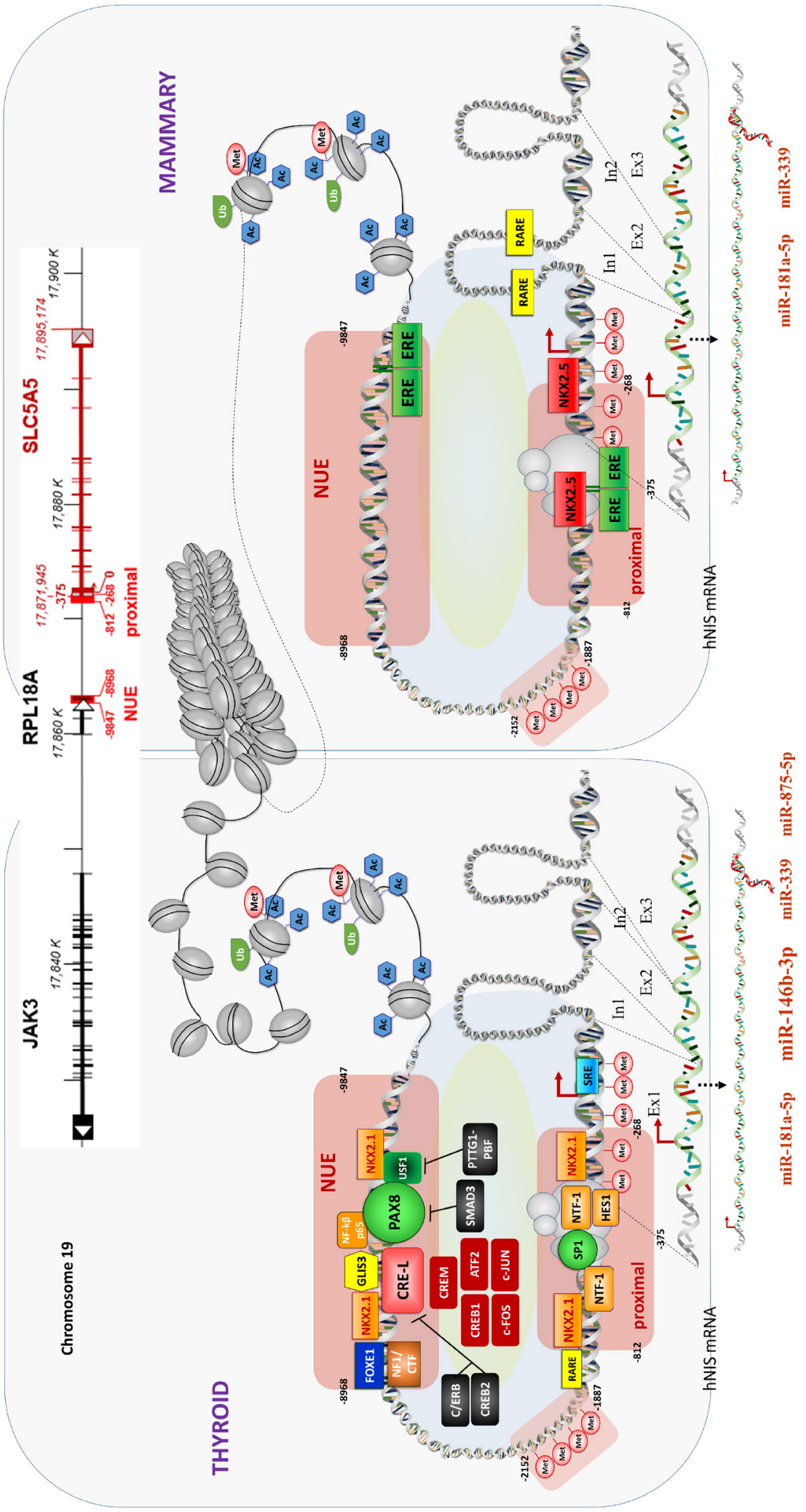

Figure 1

Transcriptional and epigenetics regulation of NIS/SLC5A5 in thyroid and mammary cells. NIS gene (SLC5A5, solute carrier family 5 member 5 ) is localized in the human chromosome 19 from $17,871,945$ to $17,895,174 \mathrm{bp}$, in a span of 23,230 nucleotides (in the latest assembly CRCh38.p13). In mice, it is localized at chr8 and in rats, at chr16. The open reading frame of 1929 nucleotides, generated by 15 exons, encodes a human protein of 643 amino acids (aa) (rat NIS contains 618 aa). SLC5A5 gene regulation starts with epigenetics modifications (methylation and histone modification) (top), and finishes with mRNA negative regulation by miRNAs, mainly by miR-146b-3p (bottom). SLC5A5 transcriptional regulation is tissue-specific with important differences in the thyroid (left) and mammary gland (right). There are two main regulatory elements, the proximal promoter ( -268 to $-812 \mathrm{bp}$ ) and the NIS upstream enhancer ( -8968 to -9847$)$, also called NUE. In the thyroid, the PAX8 transcription factor (negatively regulated by SMAD3) binds to the NUE region and has a major role in NIS upregulation. Many other factors have been shown to bind to NUE regions such as CRE-like binding site (positively regulated by CREM, CREB1, ATF2, C-Fos, and c-Jun, or negatively regulated by CREB2 and C/ERB), FOXE1, NKX2.1, USF1 (negatively regulated by PTTG1-PBF), GLIS3, and NF-kappaB. Transcription factors that upregulate NIS expression in the thyroid and have been found to bind to the proximal promoter are NKX2.1, NTF-1, SP1, and HES1. Regulation by methylation has been observed in two regions: around the exon 1 and the most important at positions -1887 to -2152 . In the mammary gland, the NUE region does not seem to participate much in NIS regulation. In this tissue, NKX2.5 and several estrogen receptor elements (ERE) at the proximal promoter have a major role in NIS regulation. ERE elements at the NUE may also exert similar effects to PAX8, and this could occur in the mammary gland and ovary, but its specificity has not been totally demonstrated. In addition, RAR and RXR interaction in the intronic regions of NIS act like enhancers of NIS expression. 
a functional GC box (to which Sp1 protein binds) were further identified as contributing to NIS transcription at the proximal promoter (Ohmori et al. 1998, Xu et al. 2002). However, NKX2.1 exerts only a modest effect on NIS transcriptional activity. Soon after, it was demonstrated that PAX8 was a much stronger inducer of NIS transcription by binding to a distant region upstream of the proximal promoter. This region, named NIS upstream enhancer (NUE), is located between -2264 and -2495 in the rat promoter, having two PAX8 binding sites (Ohno et al. 1999) and between -9847 and -8968 in the human promoter, having one PAX8 binding site (Schmitt et al. 2002, Taki et al. 2002). In addition, NKX2.1 and FOXE1 have also been found to bind to the NUE in the rat promoter (Ohno et al. 1999, Fernández et al. 2013). Overall, the enhancer NUE is the essential regulatory element for NIS transcription in the thyroid, and although the three transcription factors that define the differentiated thyroid phenotype binding to this enhancer, it is well accepted that PAX8 is the main factor mediating NIS transcription.

In addition to the binding sites for the above transcription factors, a cAMP response element (CRElike) binding site has also been shown to be crucial in the rat and human NUE (Ohno et al. 1999, Taki et al. 2002). This is not surprising as it has been well established for decades that thyroid iodide transport activity is markedly stimulated by TSH and cAMP (Weiss et al. 1984). The NUE responds to cAMP in both PKA-dependent and -independent manners, requiring PAX8 for the full cAMP transcriptional action (Ohno et al. 1999). Moreover, several basic-leucine zipper (B-ZIP) proteins have been identified in the thyroid to bind the CRE-like site and regulate NIS transcription positively (CREM, CREB1, ATF2, c-Fos, and c-Jun) and negatively (C/ERB and CREB2) (Chun \& di Lauro 2001, Chun et al. 2004, Fenton et al. 2008). Overall, the enhancer NUE is considered the main regulator of NIS transcription in the thyroid, with both PAX8 and CRE-like binding sites being essential (Taki et al. 2002). The full activity of this enhancer seems to be cell-specific as it activates NIS transcription in thyroid cell lines but not in MCF-7 breast cancer (Taki et al. 2002). However, the expression of PAX8 in non-thyroid cells results in transcriptional activation of NUE, suggesting that tissues other than the thyroid which express PAX8 (i.e. ovary) may also be dependent on NUE activation (Riesco-Eizaguirre et al. 2014).

Other transcription factors have been involved in the transcription of NIS in the thyroid (Fig. 1 left panel). One of the most prominent is the Krüppel-like zinc finger transcription factor GLI-similar 3 (GLIS3), a transcription factor whose deficiency is associated to a syndrome characterized by neonatal diabetes and congenital hypothyroidism both in humans and mice. GLIS3 is essential for the induction of TSH-mediated NIS transcription, being able to bind the NUE region and activate it (Kang et al. 2017). Another transcription factor is nuclear factor-KB (NF-KB), a ubiquitous transcription factor that is involved mainly in inflammatory and immune responses, and more specifically, it has been involved in thyroid autoimmune diseases, thyroid orbitopathy, and thyroid cancer, being fundamental for the expression of the main thyroid-specific genes (Giuliani et al. 2018). There is a conserved NF-KB site within the NUE region, and NF-KB p65 subunit appears to physically interact with PAX8 inducing a synergistic effect on NIS transcription in response to certain stimuli such as lipopolysaccharides (LPS) (Nicola et al. 2010).

In addition to GLIS-3 and NF-KB, there is a binding site for upstream stimulating factor 1 (USF1) that lies within the PAX8 consensus being this overlapping PAX8/USF1 sequence highly conserved among species (Lin et al. 2004). USF are ubiquitously expressed proteins, which belong to the basic helix-loop-helix (HLH) leucine zipper family of transcription factors and are also involved in FOXE1 regulation (Landa et al. 2009). Discrete mutation of the USF1 site resulted in a significant disruption of promoter activity suggesting that USF1 binding is required for full hNUE activity (Boelaert et al. 2007). The PAX8/USF1 site plays a critical role in mediating the repression of PTTG and PBF on the human NIS promoter (Boelaert et al. 2007). Primary tumor-transforming gene 1 (PTTG1), a proto-oncogene originally identified in pituitary tumors (Pei \& Melmed 1997) and the cofactor PBF (PTTG1-binding factor), essential for PTTG1 to be functional, is overexpressed in thyroid cancer and has been proven to be tumorigenic in both cell lines and transgenic mice repressing iodide uptake (Stratford et al. 2005, Read et al. 2011). Finally, retinoic acid (RA), a derivative of vitamin A known for its potent proliferationinhibiting and differentiation-inducing properties, exerts its regulatory effect on hNIS promoter through a retinoic acid response element (RARE) located at -1375 relative to the ATG codon (Schmutzler et al. 2002). While RA treatment of normal non-transformed thyrocytes resulted in decreased iodide uptake and reduced NIS expression, RA treatment of human follicular thyroid carcinoma cell lines had the opposite effect, both NIS mRNA and iodide uptake were elevated (Schmutzler et al. 1997).
(C) 2021 Society for Endocrinology Published by Bioscientifica Ltd. Printed in Great Britain 


\section{In the mammary gland}

NKX2.5, a transcription factor that belongs to the NK2 family (which includes NKX2.1), is a potent inducer of the NIS proximal promoter in the breast by binding to two specific sites (Dentice et al. 2004) (Fig. 1 right panel). This is surprising because, although the consensus binding sites of NKX2.5 and NKX2.1 are virtually identical, NIS is only weakly responsive to NKX2.1 in the thyroid. NKX2.5 is expressed in the heart and in the thyroid primordium during development (Lints et al. 1993), and mutations affecting this gene have been reported in individuals with congenital hypothyroidism, with NKX2.5 null embryos having thyroid bud hypoplasia (Dentice et al. 2006). However, NKX2.5 is virtually absent from the adult human thyroid and thus unlikely to be involved in maintaining NIS expression in the adult thyroid. Curiously, NKX2.5 is expressed in papillary thyroid carcinomas and its presence correlates to better prognosis (Penha et al. 2018). Importantly, NKX2.5 is expressed in mammary glands during lactation as well as in breast cancer, being critical in RA-induced NIS up-regulation in MCF-7 cells (Dentice et al. 2004).

In addition to NKX2.5, there are several estrogen receptor element (ERE) sites upstreaming NIS (Fig. 1 right panel), one in the proximal promoter and two ERE sites in the NUE. Estrogens regulate NIS expression in vivo in lactating mammary gland as well as in the ovary and fallopian fimbriae during the reproductive cycle, yet they seem to act through different transcriptional elements (Tazebay et al. 2000, Riesco-Eizaguirre et al. 2014). Also, they may have a regulatory role in the thyroid gland (Furlanetto et al. 1999). Estrogens mediate their effects in target tissues through two members of the nuclear receptor superfamily, estrogen receptor- $\alpha(E R \alpha)$ and ER $\beta$. In breast cells, experimental evidence has shown that ER $\alpha$ strongly stimulates NIS transcriptional activity at the proximal promoter in both ligand-dependent and -independent manner, yet the NUE was not analyzed in this study (Alotaibi et al. 2006). However, RA, which stimulates NIS gene transcription only in the presence of active ER $\alpha$, solely acts at the proximal promoter but not at the NUE (Alotaibi et al. 2010). By contrast, in the ovary and fallopian fimbriae, ER $\alpha$ strongly stimulates NIS transcriptional activity at the NUE in both liganddependent and -independent manner, but very weakly at the proximal promoter (Riesco-Eizaguirre et al. 2014). ER $\beta$ had little effect on its own, antagonizing the positive effects of ER $\alpha$ on NIS transcription in the ovary (RiescoEizaguirre et al. 2014). Interestingly, in the ovary, PAX8 significantly cooperates with ER $\alpha$ on NIS transcription suggesting that there is a synergism between ER $\alpha$ and PAX8 upon NIS transcriptional activation at the NUE region (Riesco-Eizaguirre et al. 2014). In the thyroid, ERs seem to be operating in the opposite way, as estradiol inhibits TSH-induced NIS expression in FRTL5 cells (Furlanetto et al. 1999).

NIS regulation by RA in breast cancer cells has been extensively reviewed (Kogai \& Brent 2012, Alotaibi et al. 2017). In contrast to the thyroid gland, in the mammary gland, an alternative enhancer in the first intron of NIS has been shown to mediate direct regulation by alltrans-retinoic acid (tRA)-stimulated nuclear receptors (Alotaibi et al. 2010). tRA is a potent ligand that enhances NIS expression in several breast cancer cell lines and in experimental breast cancer models. In vitro as well as in vivo DNA-protein interaction assays have revealed a direct association of retinoic acid receptor-alpha (RAR $\alpha$ ) and retinoid X receptor (RXR) with this intronic enhancer. Moreover, multiple introns of NIS gene (7 out of 14 introns) contain identical functional RARE sequences potentially interacting with the NIS promoter and regulating the transcriptional activation of the symporter (Alotaibi et al. 2010). In addition, because tRA-upregulated NIS expression is restricted to ER $\alpha$-positive mammary gland cell lines (Alotaibi et al. 2006), these intronic elements stimulate the initiation of NIS gene transcription only in the presence of active ER $\alpha$. RA induction of NIS in MCF-7 cells is mediated by rapid activation of the PI3K pathway and involves direct interaction with RAR and retinoid $\mathrm{X}$ receptor (Ohashi et al. 2009).

\section{General view}

Overall, different regulatory elements on NIS gene with varying degrees of enhancer and promoter activities operate depending on the species and tissue context to modulate NIS transcription (Fig. 1). In the thyroid, there are a low proximal promoter and a high NUE activity mediated by TSH/cAMP stimulation that acts through a synergism between PAX8 and CRE-like binding sites. In the lactating mammary gland, there is a high proximal promoter but low NUE activity ruled by estrogens and other lactogenic hormones that act through NKX2.5 and ER $\alpha$; in this setting, an enhancer on intron 1 based on RARE elements strongly potentiates NIS transcription through RA stimulation. In the ovaries, there is a low proximal promoter and high NUE activity due to a synergism between ER $\alpha$ and PAX8, most likely under the control of gonadotrophins.
(C) 2021 Society for Endocrinology Published by Bioscientifica Ltd. Printed in Great Britain 


\section{Epigenetic modification on NIS gene}

Epigenetic modification alters the regulation of gene expression mainly by three mechanisms: DNA methylation, histone modification, and nucleosome positioning (Portela \& Esteller 2010). The modifications observed are usually the sum of different interactions of epigenetic factors, as well as positive and negative feedback mechanisms. miRNAs, also considered an epigenetic phenomenon, will be included in the next section.

\section{DNA methylation}

DNA methylation of CpG dinucleotides tends to cluster in CpG-islands, or in CpG-island shores in regions of lower CpG density. In normal human cells, about $60 \%$ of the promoters are usually unmethylated or methylated in a tissue-specific manner during early development or in differentiated tissues (Portela \& Esteller 2010). Aberrant DNA methylation plays a crucial role in thyroid carcinogenesis (Xing 2007, Zafon et al. 2019). Typically, papillary thyroid carcinomas (PTC), poorly differentiated thyroid carcinomas (PDTC), and anaplastic thyroid carcinomas (ATC) exhibit more hypomethylation and less hypermethylation events than in normal thyroid tissues but the contrary occurs in follicular thyroid carcinomas (FTC). This pattern also differs with respect to the driver mutation, with BRAF-mutated tumors harboring more hypomethylations and RAS-mutated tumors more hypermethylation (Agrawal et al. 2014).

Examination of $5000 \mathrm{bp}$ in the $5^{\prime}$ region of the NIS gene has identified two CpG-islands, the first one between nucleotides -466 to +246 and the second one between nucleotides -2152 and -1887 relative to the ATG site (Fig. 1) (Venkataraman et al. 1999, Galrão et al. 2014). NIS gene methylation status has been explored in normal thyroid tissue and benign and malign thyroid tumors, including several thyroid cancer cell lines. The methylation levels in the first CpG-island were similar in tumoral and non-tumoral surrounding thyroid samples, and no correlation was observed between NIS mRNA expression and methylation status (Neumann et al. 2004). Interestingly, the degree of methylation of the second CpG-island in tumoral tissues was significantly higher than in non-tumoral tissues in the benign and malignant groups, and a significant inverse correlation with NIS mRNA expression was discovered (Galrão et al. 2014). Functional analysis showed that this region is not a promoter region but has regulatory activity. Because the hypermethylation pattern was detected in both benign and malignant thyroid tumors, the authors suggest that the deregulation of NIS methylation is an early event in tumorigenesis. Other authors have also observed hypermethylation of NIS gene in PTC and FTC tumors when compared with normal tissues (Smith et al. 2007, Stephen et al. 2011) An interesting work by Choi et al. found that the association of BRAFV600E mutation and NIS down-regulation is mediated by high expression of DNA methyltransferase 1 (DNMT1) (Choi et al. 2014).

Several groups have attempted the use of demethylation agents as a strategy to restore NIS function in thyroid cell lines with contradictory results. In some cases, the results have been positive (Venkataraman et al. 1999, Galrão et al. 2014), but in others, the results have been modest or negative, even though some of the cell lines were the same (Tuncel et al. 2007, Massimino et al. 2018). Currently, there are several clinical trials underway testing the use of 5-AZA or analogs in thyroid cancer. Intravenous decitabine (5-AZA) injected in 12 patients with metastatic papillary or follicular thyroid tumors did not restore iodide accumulation in patients (NCT00085293). Azacitidine is currently being evaluated in a phase 1 trial (NCT00004062).

\section{Histone modification}

One of the most important events in gene regulation is histone acetylation and deacetylation. Histone acetylation status is regulated by the opposing activity of histone acetyltransferases (HAT) and histone deacetylases (HDAC). Histone acetylation promotes gene expression, while deacetylation promotes repression of gene expression (Verdone et al. 2006). HDACs play a key role in cancer induction and progression, including thyroid cancer (Russo et al. 2013). NIS gene transcription regulation by histone acetylation at the promoter region has been demonstrated. This opened the challenge to prove whether HDAC inhibitors could be useful to restore NIS activity, not only in aggressive thyroid cancers (Puppin et al. 2005, Provenzano et al. 2007) but also in cell lines derived from non-thyroid NIS-expressing tumors such as breast, melanoma, liver, gastric, colon, cholangiocarcinoma, and Leydig testicular carcinoma (Kogai \& Brent 2012).

However, there has been a great disparity among studies. Initial results were more promising, but they have not always been reproduced by other laboratories. Regardless of the thyroid tumor subtype, it has been observed that cell lines with mutations in BRAF and HRAS respond worse to treatments with HDAC inhibitors than those with other types of gene alterations. In addition, the presence of MAPK and PI3K/Akt inhibitors sometimes 
improves results. However, results in non-thyroid NISexpressing cell lines are more complex and harder to analyze. Perhaps the most revealing experiment in preclinical trials has been the study performed with five samples from PDTC and ATC patients implanted in mice (Wächter et al. 2018). When treated with the HDACi Panobinostat, they observed an increase in the expression of mRNA levels of NIS in all tumors, but they only observed a very modest increase in the accumulation of radioiodide in one of them. Similar results were obtained when using the tyrosine kinase inhibitors (TKIs) sorafenib and selumetinib. In spite of modest results of tumoral NIS re-expression/function, it could be enough for radioiodide treatment to be effective. This has prompted numerous clinical trials to emerge. However, the results of clinical trials in advanced thyroid cancer or radioiodide-refractory differentiated thyroid cancer have been a bit disappointing. Evaluation with the HDAC inhibitors SAHA (Kelly et al. 2005), romidepsin (Amiri-Kordestani et al. 2013), vorinostat (Woyach et al. 2009), and valproic acid (VPA) (Nilubol et al. 2017) and depsipeptide (Xu \& Hershman 2006) have not given the expected results.

The results of clinical trials with either demethylation or HDAC inhibitors highlight three important aspects. First, that the transcriptional regulation of NIS is much more complex than we can ascertain in in vitro experiments; secondly, transcription is only one part of the puzzle, understanding NIS trafficking to the membrane is a key element to fully reach NIS function; thirdly, that clinical trials must be preceded by robust molecular data and preclinical trials.

\section{Challenges in understanding miRNA function in NIS regulation}

\section{NIS as a target for miRNAs}

Typically, miRNAs negatively regulate gene expression; they either inhibit translation or induce mRNA degradation usually by binding to the 3'UTR of target mRNAs. Based on in silico predictions and experimental evidence, a number of miRNAs have been shown to target the 3'UTR of NIS and reduce its expression. miR-146b-3p, one of the most abundant and upregulated miRNAs in PTC, binds to one single specific site of the 3'UTR of NIS mildly reducing its expression (Riesco-Eizaguirre et al. 2015). In accordance with these data, antagonizing miR-146b-3p in human thyroid cancer cells reinduces NIS-mediated iodide uptake (Li et al. 2015, Hou et al. 2020). More importantly,
miR-146b-3p also binds specifically to three sites in the 3'UTR of PAX8 repressing its expression (Riesco-Eizaguirre et al. 2015). Thus, miR-146b-3p not only represses NIS directly but also indirectly through the repression of its main transcription factor, PAX8. The importance of miR-146b-3p was highlighted in the large cohort of the cancer genome atlas (TCGA) analyzing over 500 tumor samples of PTC, as this miRNA was one of the three miRNAs that most strongly negatively correlated with the expression of iodide-metabolizing genes (Agrawal et al. 2014).

Other miRNAs have been shown to repress NIS. miR-339 binds to the 3'UTR of NIS and is able to repress its expression in TSH-stimulated $\mathrm{PCCl} 3$ rat thyroid cells and in MCF-7 human breast cancer cells treated with trans retinoic acid/hydrocortisone (Lakshmanan et al. 2015a). However, this miRNA is not among the most abundantly upregulated miRNAs in thyroid carcinomas. miR-875-5p, a miRNA highly expressed in PDTC, also targets 3'UTR and represses NIS in PDTC cell lines (Tang et al. 2020). miR-17-92, a cluster that comprises several miRNAs and is highly expressed in human ATC, has also been shown to repress NIS and PAX8 among other iodide-metabolizing genes (Fuziwara et al. 2020). Silencing of miR-17-92 via CRISPR/Cas9n gene editing induced a partial restoration of a differentiated phenotype characterized mainly by reestablishing expression of NIS, TG, TPO, PAX8, and NKX2.1. Several members of the cluster such as miR-19, miR-92, and miR-17 repress NIS, NKX2.1, and PAX8 protein levels. However, although the 3'UTR segment of rat Pax 8 mRNA contains predicted sites for miR-17-5p and miR-20a-5p, the authors failed to demonstrate an interaction between the miRNAs and the 3'UTR of PAX8 through luciferase reporter assays. Nevertheless, this work supports the idea that miRNAs preferentially target lineage transcription factors to repress NIS and induce loss of differentiation.

\section{miRNA-transcription factor co-regulation}

Increasing evidence suggests that a complex interplay exists between the two largest classes of transcriptional and posttranscriptional regulators - transcription factors and miRNAs - to buffer gene expression and/or potentiate signaling (Bracken et al. 2016). Reciprocal feedback loops in which a miRNA and transcription factor co-regulate the expression of one another constitute a recurring network motif that occurs more often than predicted by chance (Martinez et al. 2008). Indeed, experimental evidence shows that PAX8 induces the transcription of miR-146b having several binding sites in its regulatory region and, 
hence, PAX8 limits its own activity by inducing its own repressor, miR-146b-3p (Riesco-Eizaguirre et al. 2015). This constitutes a reciprocal feedback loop in which the miRNA and the transcription factor co-regulate the expression of one another. Other network motifs between miRNAs and transcription factors include coherent and incoherent feedforward loops, whereby miRNAs and transcription factors regulate common targets. In thyroid cells, miR-146b-3p represses PAX8 and its downstream target NIS, as mentioned earlier. This miR-146b-PAX8-NIS circuit is an example of an incoherent feedforward loop whereby the transcription factor and miRNA have opposing (buffering) effects. These network motifs based on miRNAtranscription factor interactions are thought to strongly induce the propagation of the signal through the cell and explain why miRNAs can have a major impact on cell behavior, yet only modestly regulate most of their direct targets (Bracken et al. 2016).

The spreading of regulatory effects exerted by co-regulation of PAX8 and miR-146b sets an example of what may be operating in the thyroid cell. In fact, PAX8 and miR-146b share other common target genes such as IYD (DEHAL) and DIO2 that are metabolizing-iodide genes influencing iodide uptake (Riesco-Eizaguirre et al. 2015). Other miRNAs-transcription factor regulation pairs may also be operating with other lineage transcription factors such as FOXE1 and NKX2.1 to regulate common iodidemetabolizing target genes (Riesco-Eizaguirre \& Santisteban 2016). The extent to which the influence of miRNAs is mediated, not just directly through their primary targets but also indirectly through the action of the transcription factors they regulate, has been well established (Gosline et al. 2016). Most of the overall gene expression changes after miRNA perturbation through DICER RNase silencing occurred at the level of transcription, rather than posttranscriptionally. Particularly, DICER1 silencing in thyroid cells (which consequently depletes most miRNAs) decreased PAX8 and NKX2.1 expression and subsequently decreased NIS expression and activity (Ramírez-Moya \& Santisteban 2021).

\section{Some cautionary notes on miRNAs}

To establish the role of miRNAs, we should consider their place in a network system and their capacity to target hubs in such networks. NIS is not a common direct target for miRNAs. The reason is that NIS 3'UTR is not conserved among species and algorithms predicting mRNA targets are largely based on how well conserved the 3'UTR is among species. Thus, NIS does not seem to be a hub in a network system. By contrast, PAX8 and other transcription factors are targets of several upregulated miRNAs in thyroid cancer, with their 3'UTR being well conserved among species and having strong scores according to in silico predictions. Another important issue when considering miRNAs function is their abundancy. Abundantly expressed miRNAs (i.e. miR-21, miR-146b) are expressed at thousands of copies per cell, which is sufficient to affect many different mRNAs (Bracken et al. 2016). However, many miRNAs, while detectable in many tissues and tumors, are lowly expressed and their function is unlikely to have a real effect. Therefore, positioning miRNAs and their targets in a network system and considering their abundancy in a certain tissue are key aspects if we really want to know the biological impact of such molecules.

\section{Hormones, growth factors, and iodide}

I- $^{-}$accumulation is an active transport process finely regulated by the endocrine system in a tissue-specific manner. NIS is regulated in the thyroid, the mammary glands, and the ovaries by different hormones in different ways (Table 1). In addition, several growth factors and cytokines may be acting in a more paracrine manner in the tissue microenvironment. Here we will focus on the role played by TSH, lactogenic hormones, cytokines (i.e. TGF $\beta$ ), and iodide itself. All of them elicit not only a physiological role on NIS expression but also are at the core of important pathological situations.

\section{TSH}

TSH, a glycoprotein produced by thyrotrophs in the anterior pituitary, is the major regulator of thyroid function. It is well known that TSH stimulates I- uptake in thyroid cells. Therefore, this hormone has been identified as the main regulator of NIS expression in the thyroid as it strongly increases NIS mRNA and protein levels (Kogai et al. 1997). TSH mediates its action through $G$ protein coupling receptors (GPCR), mainly by activation of Gasmediated cAMP production. Although a TSH-responsive element, named Ntf-1, was identified in the rat proximal promoter, its activation in response to TSH is minimal (Ohmori et al. 1998), as mentioned in the previous section (Fig. 1). On the contrary, the NUE site is the regulatory region that recapitulates the action played by TSH and, as we will see later, by IGF1 and TGF $\beta$. The NUE site activates transcription in a cAMP-dependent manner, mediated 

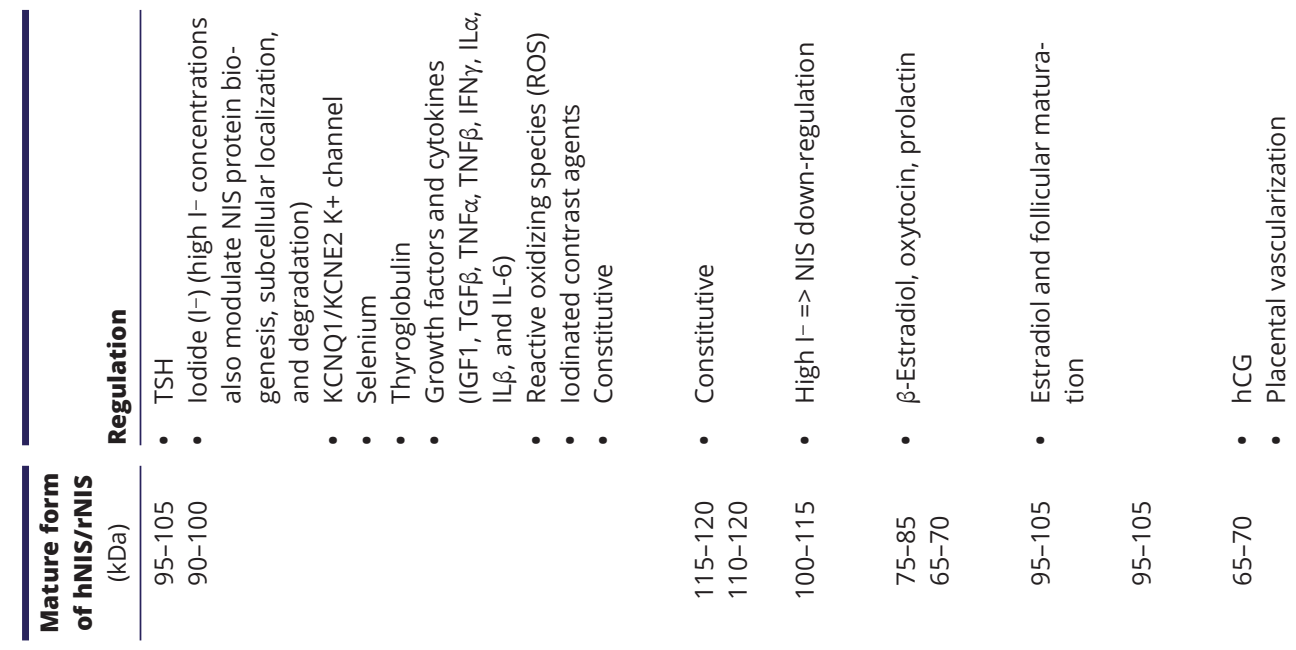

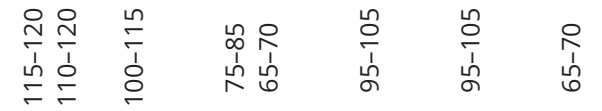
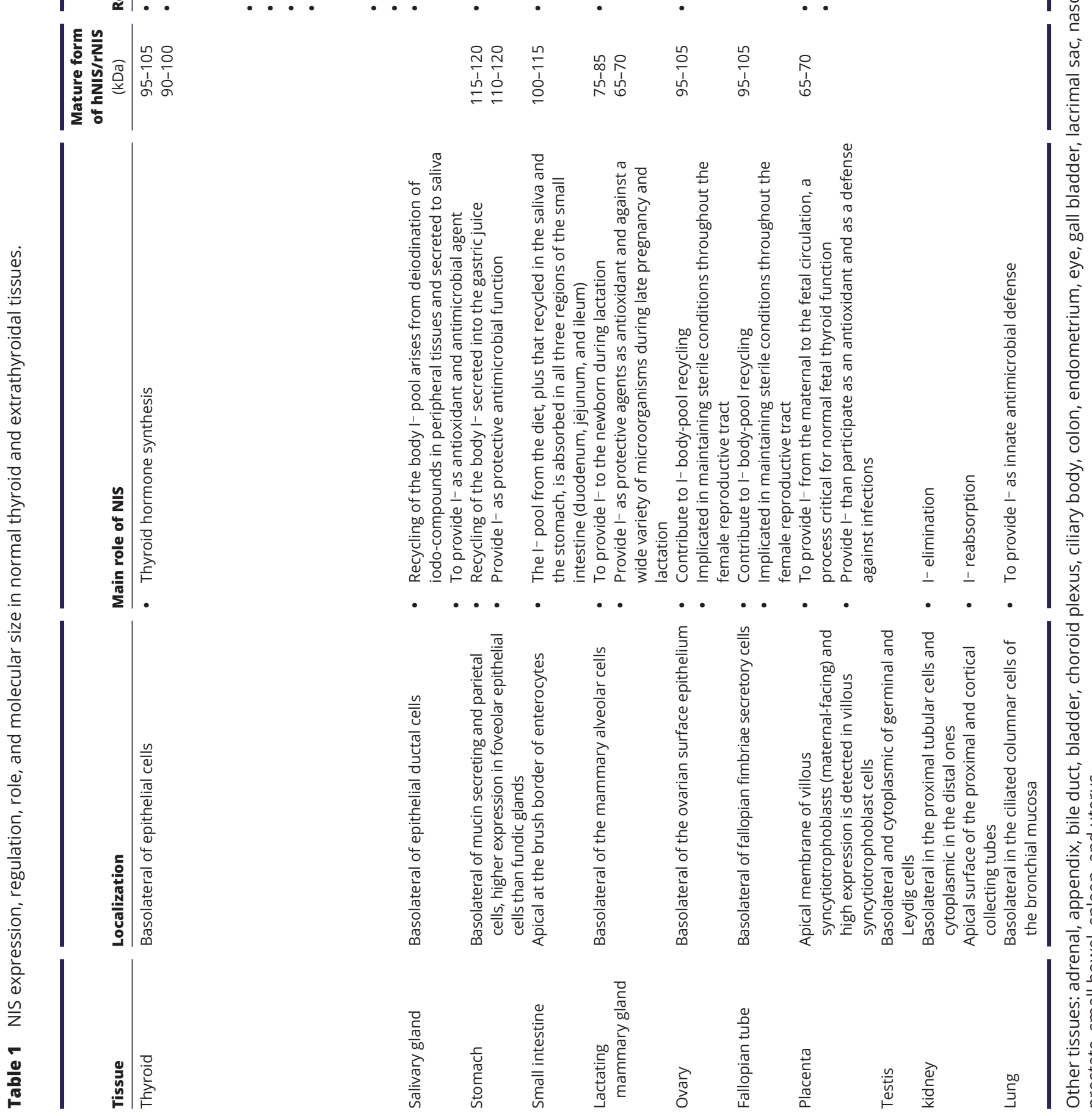
by both PKA-dependent and independent pathways (Ohno et al. 1999, Taki et al. 2002, Chun et al. 2004). The mechanism involves a synergistic action between PAX8 and several other factors binding to the CRE-like site (see previous section) (Ohno et al. 1999).

Although the TSH effect on NIS expression and function is mainly mediated by activation of Gasmediated cAMP production, TSH also induces the release of other $G$ proteins such as $G \beta \gamma$ dimers (Fig. 2). These $G \beta \gamma$ dimers stimulate PI3K signaling which in turn inhibits NIS gene expression in a cAMP-independent fashion due to a decrease in PAX8 binding to the NIS promoter (Zaballos et al. 2008). This action of TSH occurs mainly at high doses of the hormone, a mechanism that is thought to counterbalance the accumulation of iodide in the gland.

Finally, the TSH effect is not only elicited at a transcriptional level. Several data suggest that mechanisms other than transcriptional operate to regulate NIS activity in response to TSH (Kogai et al. 1997). TSH increases NIS protein, modifies its glycosylation, and influences its location at the basolateral membrane and its redistribution inside the cell vesicles (Levy et al. 1998, Riedel et al. 2001) (see also NIS traffic regulation section).

In summary, all these data reveal that TSH is the major regulator of NIS activity and $\mathrm{I}^{-}$accumulation into the thyroid gland. TSH regulates NIS at a transcriptional, posttranscriptional, and posttranslational level, underscoring the complexity and multi-level regulation of NIS in physiological conditions.

\section{Estrogen and lactogenic hormones}

NIS is expressed in the mammary gland and in the ovary and fallopian fimbriae only in certain physiological conditions that seem to be related with the rise of estrogens and other hormones (Table 1). NIS expression in the mammary gland progressively increases toward the end of gestation and is most prominent during lactation. In vivo experiments in ovariectomized mice show that the combination of estrogen, prolactin, and oxytocin (in the absence of progesterone) leads to the highest levels of NIS expression in the mammary glands (Tazebay et al. 2000, Dohán et al. 2006). This combination of hormones closely resembles the relative hormonal levels in mice and rats during lactation. Of note, of all the hormones tested individually, only $17-\beta$-estradiol led to a clearly discernible increase in NIS expression, but not oxytocin or prolactin. The ovary and the fallopian fimbriae express NIS, accumulating a significant amount of radioiodide in vivo both in rats and humans, being highest under maximum estrogen exposure during the reproductive cycle. This important role of estrogens in regulating ovarian NIS is reinforced by evidence demonstrating that ER $\alpha$ strongly stimulates NIS transcriptional activity in both ligand-dependent and -independent manner at the NUE region (RiescoEizaguirre et al. 2014). However, in the thyroid, ERs seem to be operating in the opposite way, as estradiol inhibits TSH-induced NIS expression in FRTL5 cells (Furlanetto et al. 1999).

\section{Cytokines and growth factors}

TSH upregulates rat NIS gene expression in vitro, and this induction can be modulated by cytokines. Early studies demonstrated that cytokines including interleukin-6 (IL-6), interferon-gamma (IFN- $\gamma$ ), tumor necrosis factor-alpha (TNF- $\alpha$ ), IL- $1 \alpha(100 \mathrm{U} / \mathrm{mL})$, IL-1 $\beta$, and TGF $\beta$ downregulated NIS function to a greater or lesser extent (Ajjan et al. 1998, Pekary et al. 1998, Spitzweg et al. 1999) (Table 1). Both infiltrating inflammatory cells and thyroid follicular cells produce cytokines, which affect thyroid function and growth and cause immunological changes in the gland. As cytokines are involved in the pathogenesis of autoimmune thyroid disease such as Graves' disease and Hashimoto's thyroiditis, they may explain in part the changes in NIS expression patterns seen in such forms of autoimmune thyroid disease, as well as the mechanism underlying autoimmune hypothyroidism.

Among cytokines, the mechanism played by TGF $\beta$ has been the most studied (Fig. 2). TGF $\beta$ exerts an inhibitory effect on thyroid function, including a decrease in NIS expression and $\mathrm{I}^{-}$uptake (Kawaguchi et al. 1997, Pekary et al. 1998). TGF $\beta$ decreases NIS expression by reducing TSH transcriptional activation. The region responsible for this effect is the enhancer NUE, and the mediator of this action is the SMAD3 protein which interacts with PAX8 inhibiting its binding to NUE and, therefore, impairing NIS transcription (Costamagna et al. 2004). TGF $\beta$ plays a key role in thyroid cancer as BRAFV600E, the most prevalent oncogene in thyroid cancer, is a strong inducer of TGF $\beta$ secretion both in vitro and in vivo (Riesco-Eizaguirre et al. 2009, Knauf et al. 2011), taking part in tumor progression and dedifferentiation (see 'Hormones, growth factors, and iodide' section) (Fig. 2). In addition, the inhibitory effect of TGF $\beta$ on NIS expression is not exclusive of thyroid tissue as TGF $\beta$ inhibits NIS mRNA and protein expression in cultured mammary gland explants from lactating mice (Yu et al. 2012). Lately, another cytokine, TNF- $\alpha$, an activator of NF- $\kappa \mathrm{B}$ with a central role in thyroid autoimmunity, has been studied in more detail. TNF- $\alpha$ downregulates 
A

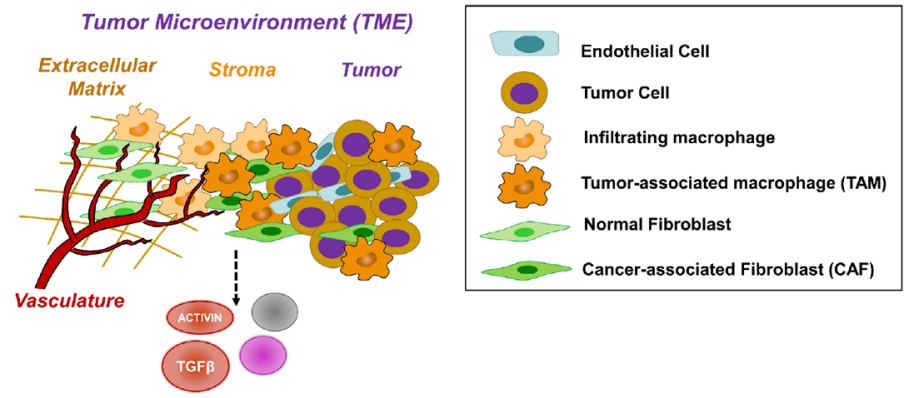

B

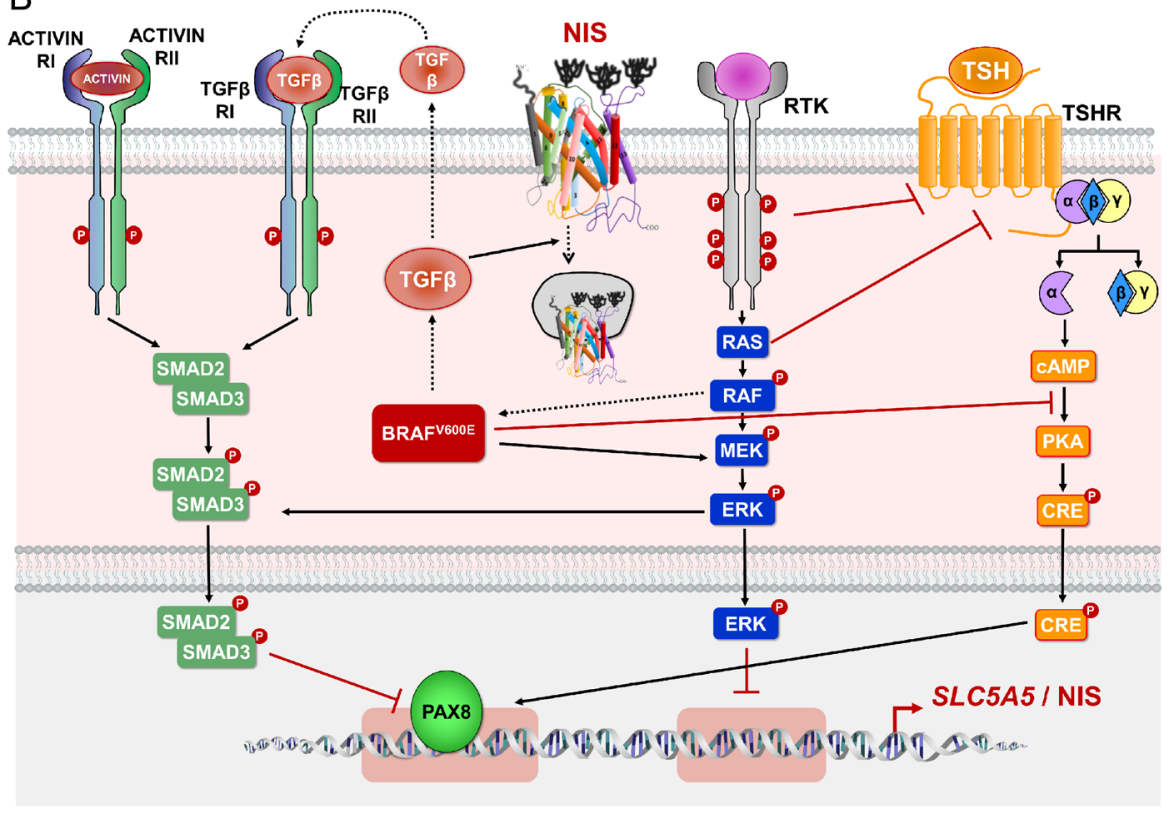

C

TGF $\beta_{1}$

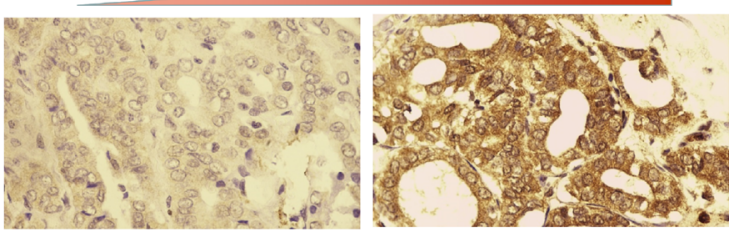

Tumor Center

Invasive front
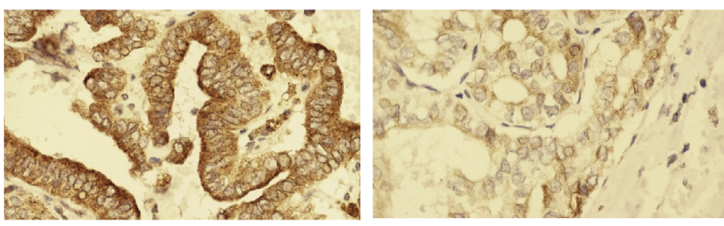

NIS

Figure 2

Crosstalk between the MAPK and TGF $\beta$ signaling pathways leading to NIS repression in thyroid cancer. (A) Tumor-associated macrophages and other cells from the stroma in the tumor microenvironment contribute to TGF $\beta 1$ secretion and other ligands such as activin. (B) In thyroid cancer cells, BRAFV600E induces a strong TGF $\beta 1$ and activin secretion, promoting an autocrine loop that evokes a SMAD3-dependent downregulation of PAX8 and inhibition of its binding to the NUE promoter. BRAFV60E also induces pERK phosphorylation at the T8 residue of SMAD, promoting its additional phosphorylation and activation by the TGF 1 receptor. RET/PTC and BRAFV00E also decrease expression of the TSHR, which could also explain in part NIS repression and loss of differentiation. In addition, BRAFV600E, but not RET/PTC, inhibits CAMP-induced levels of NIS, suggesting an alternative mechanism distal to CAMP through unknown mechanisms that are SMAD-independent. Finally, BRAFV600E also impairs NIS targeting to the plasma membrane, likely through TGF $\beta 1$. (C) Immunoreactive TGF $\beta 1$ is strongly increased in the invasive front of PTCs, whereas NIS expression is present mainly in the central areas of the tumors but not in the invasive front, suggesting that a negative correlation between TGF $\beta 1$ and NIS occurs also locally inside the tumor. 
TSH-induced NIS expression in the thyroid follicular cell through NF-kB activity (Pekary et al. 1998, Faria et al. 2020).

In addition, studies carried out prior to the cloning of NIS in FRTL5 thyroid cells showed that in the absence of serum, IGF1 and insulin impaired the ability of TSH/cAMP to induce iodide uptake (Saji \& Kohn 1991). After the cloning of NIS, it was demonstrated that IGF1 inhibits the TSH/cAMP-induced NIS expression at the transcriptional level (García \& Santisteban 2002). This transcriptional effect involved NIS promoter region closed to NUE, and unpublished results of our laboratory have shown that IGF1 inhibits the binding of PAX8 to NUE (García B, Costamagna E \& Santisteban P, unpublished observations). This inhibitory effect is mainly mediated by PI3K activation, as AKT inhibitors restore iodide uptake in the presence of IGF1. Because PI3K/AKT/mTOR signaling pathway is one major pathway driving cancer growth in thyroid cancer (Xing 2010), targeting this pathway with inhibitors may be a good therapeutic strategy to reinduce NIS expression and iodide uptake.

\section{Is NIS a major autoantigen?}

In the late 1990s, the hypothesis that NIS represented a major thyroid autoantigen that elicits the formation of functionally relevant autoantibodies attracted much attention (Spitzweg \& Morris 2000). NIS-directed antibodies are present in sera from patients with autoimmune thyroid disease, and these antibodies may also affect NIS functional activity. However, convincing evidence further showed that NIS-directed autoantibodies occur with low frequency among a large sample of patients with autoimmune thyroid diseases (Seissler et al. 2000). In addition, no evidence of specific iodide uptake inhibiting activity was obtained once sera had been subjected to dialysis and/or IgG extraction (Chin et al. 2000, Tonacchera et al. 2001). Moreover, when detected in addition to TPO and TSH receptor autoantibodies, NIS-directed autoantibodies do not appear to contribute any diagnostic power for Graves' disease and Hashimoto's thyroiditis (Heufelder et al. 2001). Therefore, NIS does not appear to be a major functionally relevant antigen in autoimmune thyroid diseases.

\section{lodide}

Another regulator of NIS function is iodide itself (Table 1). It has been long established that an excess of iodide inhibits its own transport into the thyroid cell (Braverman \& Ingbar 1963). Inhibition of iodide transport in FRTL5 cells by an excess of iodide seems to be mediated by an intracellular iodinated compound, as methimazole (MMI), an inhibitor of iodide organification, prevented such effect (Grollman et al. 1986). After the cloning of NIS in 1996, however, it became clear that NIS response to an excess of iodide was more complex than initially thought, with dissimilar results in rat thyroids in vivo than in thyroid cultured cells. In rats, an excess of iodide decreases NIS mRNA and protein levels at 1 and 6 days in what seems to be, at least in part, a transcriptional mechanism most likely mediated by an intracellular iodinated compound (Eng et al. 1999, Leoni et al. 2011). However, at shorter times (i.e. $5 \mathrm{~h}$ ), the decrease of iodide uptake in rats cannot be attributed to a transcriptional mechanism because there is a much modest variation on mRNA or protein levels (Leoni et al. 2011). Moreover, it can neither be attributed to impaired NIS trafficking as the symporter remains at the plasma membrane (Arriagada et al. 2015). This suggests that, in addition to a transcriptional mechanism, an early posttranslational mechanism is taking place in vivo. On the other hand, in cultured thyroid cells (FRTL5 and PCCL3) this posttranslational mechanism seems to be most prominent. While a strong inhibition of iodide uptake both at short (2-5 h) and long times (24-72 h) intervals is seen, the effect on NIS mRNA and protein levels is transient and much more modest than in rats (Leoni et al. 2011, Arriagada et al. 2015). Moreover, neither NIS promoter activity nor PAX8 expression or its binding to DNA was modulated by ioidide in vitro.

Therefore, thyroid cultured cells are excellent models to study the posttranslational effect of iodide excess on NIS. One possible mechanism is based on alterations in the redox state. Iodide excess triggers an early and sustained increase in reactive oxidative species (ROS) production which in turn induces posttranslational modifications in NIS at the plasma membrane (Leoni et al. 2011). The inhibitory effect on NIS-mediated I- transport could be recapitulated by $\mathrm{H}_{2} \mathrm{O}_{2}$ and reverted by reactive derived oxygen species scavengers (Arriagada et al. 2015). On the contrary, inhibition of the selenoprotein thioredoxin-reductase, which increases ROS production, increased NIS inhibition induced by iodide excess (Leoni et al. 2011). This attractive hypothesis suggests that the redox state of thyroid cells directly modulates NIS activity, perhaps through the effect on aa modifications or the oligomeric state of the symporter. In support of this, another modulator of the redox state such as selenium seems to increase iodide uptake through a reduction of ROS species (Leoni et al. 2016).

Understanding the effects of iodide excess on NIS function have important clinical implications. Excess of $\mathrm{I}^{-}$inhibits the synthesis of $\mathrm{TH}$, a process described a long 
time ago and known as the Wolff-Chaikoff effect (Wolff \& Chaikoff 1948). Wolff and Chaikoff reported that high plasma iodide levels blocked iodide organification in rat thyroid in vivo leading to a reduction in the synthesis of thyroxine. However, there is an 'escape' or adaptation from this acute Wolff-Chaikoff effect that restores normal TH biosynthesis in approximately 2 days even in the continued presence of high plasma I- concentrations (Wolff \& Chaikoff 1949). It has been postulated that recovery of thyroid function is mediated by the early inhibition of I- uptake through a reduction of NIS activity, which would alleviate the high intracellular iodide concentrations and restore TH biosynthesis (Braverman \& Ingbar 1963, Eng et al. 1999, 2001). As mentioned earlier, the molecular mechanisms underlying this adaptive effect seem to be most related to the redox state, as iodide induces high levels of ROS impairing NIS activity. Eventually, the action of the selenoprotein thioredoxin reductase will reduce ROS production restoring NIS function (Leoni et al. 2011, De la Vieja \& Riesco-Eizaguirre 2021).

\section{Signaling pathways in NIS repression}

\section{The central role of MAPK signaling}

PTC is a MAPK-driven tumor and this signaling pathway is considered to play a major role in repressing NIS and other thyroid differentiated genes (Fig. 2). Approximately more than $80 \%$ of human PTCs are associated with mutually exclusive mutations of RET/PTC or TRK, RAS (NRAS > HRAS > KRAS), or BRAF (Kimura et al. 2003, Soares et al. 2003). The oncoproteins encoded by these genes share the common property of constitutively activating MAPK signaling, which has been taken as evidence supporting a critical role of this pathway in the pathogenesis of the disease. Further evidence provided by TCGA showed that these oncoproteins activated MAPK signaling with different intensities that directly correlated to the degree of dedifferentiation (Agrawal et al. 2014). In other words, the higher the intensity of MAPK signaling, the higher the repression of NIS and other iodide-metabolizing genes.

This concept, that the expression of NIS and other iodide-metabolizing genes are particularly sensitive to the activity of the MAPK pathway, was first pointed in PCCL3 cells, which retain most of the differentiated properties of normal thyrocytes. Conditional activation of RET/PTC oncogene downregulates the expression of NIS, TSHR, TG, TPO, and PAX8 (De Vita et al. 1998, Portella et al. 1999). Similarly, conditional expression of oncogenic RAS, BRAF, or of constitutively active MEK recapitulates the inhibitory effect on NIS which is partially restored by treatment with MEK inhibitors (Fig. 2) (Mitsutake et al. 2005, 2006, Riesco-Eizaguirre et al. 2006, Liu et al. 2007a). Both RET/PTC and BRAF decrease expression of the TSHR (Wang et al. 2003, Mitsutake et al. 2005), which could explain in part this loss of differentiation. However, the mechanisms by which RET/PTC and BRAF interfere with TSH action distal to the receptor are different. Whereas RET/PTC markedly impairs adenylyl cyclase activity (Wang et al. 2003), BRAF does not affect forskolin-induced cAMP levels. BRAF inhibits cAMP-induced levels of NIS mRNA as well as NIS protein expression and membrane targeting, suggesting an alternative mechanism distal to cAMP (Mitsutake et al. 2005, Riesco-Eizaguirre et al. 2006).

In addition to PCCL3 cells, experiments in animal models have been particularly illustrative (Knauf et al. 2005, Chakravarty et al. 2011). Transgenic mice with doxycycline (dox)-inducible expression of BRAF ${ }^{\mathrm{V} 600 \mathrm{E}}$ in thyroid follicular cells -which resembles high-grade PTCs found in humansvirtually abolished thyroid-specific gene expression including NIS and radioiodide incorporation, all of which were restored to near basal levels upon discontinuation of dox (Chakravarty et al. 2011). Discontinuation of dox also reestablished thyroid follicular architecture and normal thyroid histology which confirm an exquisite dependence on BRAF oncoprotein for transformation. Treatment with MEK or mutant BRAF inhibitors partially restored thyroidspecific gene expression and rendered the tumor cells susceptible to a therapeutic dose of radioiodide. However, these MAPK inhibitors had a more attenuated effect on the restoration of NIS expression levels, as well as those of TPO and TG, compared with those in dox-withdrawn mice, and therefore, the therapeutic effect of radioiodide treatment was weaker (Chakravarty et al. 2011). This suggests that to achieve full therapeutic benefit with MAPK inhibitors, simply dimming the signaling pathway is not enough, it needs to be almost completely suppressed, evidence of which has been shown in other cancer models (Bollag et al. 2010).

Therefore, potent inhibition of ERK signaling seems to be required to adequately induce iodide uptake, rendering tumor cells susceptible to a therapeutic dose of radioiodide. An allosteric MEK inhibitor (CKI) that functions as a dominant-negative inhibitor of RAF kinases (both WT and mutant) and reduces feedback reactivation of ERK signaling has been shown to achieve a potent and sustained inhibition of extracellular-regulated kinase (ERK) signaling in thyroid cells and in mice with BRAFV600E_ induced thyroid cancer (Nagarajah et al. 2016). The authors 
of this study found that a reduction of expression of MAPK transcriptional output markers from 70 (with selumetinib or low-dose CKI) to $85 \%$ (with high-dose CKI) had profound reciprocal effects on the expression of NIS, TG, and TSHR. Under such high-dose CKI treatment for as little as 8 days is sufficient to enable effective radioiodide therapy. However, toxicity of achieving high level ERK pathway inhibition can be a constraint on these approaches.

Subsequent clinical trials have been performed to test the effectiveness of MAPKinhibitors to restore iodide uptake and enable patients with radioactive iodide refractory thyroid cancers to be treated with high doses of I-131. The first proof-of-principle clinical trial was performed by Ho et al. from the Memorial Sloan Kettering Cancer Center in 24 patients with advanced thyroid cancer, confirming the ability of the MEK inhibitor selumetinib to restore radioiodide in tumors previously shown to be radioiodide resistant (Ho et al. 2013). This promising redifferentiation strategy has been extensively addressed in a recent review by Buffet et al., summarizing all the MAPK inhibitors tested so far, including MEK inhibitors (selumetinib and trematenib) and BRAF inhibitors (dabrafenib and vemurafenib) (Buffet et al. 2020). Nevertheless, although MAPK inhibitors have shown to increase iodide accumulation in a significant fraction of patients with refractory metastatic thyroid cancers, such inhibitors are insufficient to induce major clinical responses to radioiodide in many of them. In line with preclinical animal models, one of the conclusions from all these clinical studies reveals that the degree of iodide avidity restoration is linked to the degree of MAPK pathway output inhibition, and toxicity derived from such inhibition is a major limitation of this approach (Nagarajah et al. 2016).

\section{The crosstalk between MAPK and TGF $\beta$ signaling}

The mechanism through which MAPK signaling inhibits NIS expression relies partially on TGF $\beta$ signaling (Fig. 2). As mentioned earlier, BRAFV600E strongly induces TGF $\beta$ secretion in thyroid cancer cell lines and animal models, having a major role in EMT and tumor progression (RiescoEizaguirre et al. 2009, Knauf et al. 2011). In addition, ligands other than TGF $\beta 1$ are also activating this pathway since the activin ligand subunits Inhba and Inhbb are overexpressed in BRAFV00E-mutant thyroid cancers transgenic mice (Luckett et al. 2021) (Fig. 2B). In human samples, high levels of TGF $\beta$ and other components of the signaling pathway such as T $\beta$ RII and p-SMAD are present in aggressive PTCs, being predominantly expressed in the invasive front of the primary tumors as well as in lymph node metastases, suggesting a widespread activation of this pathway by locally released TGF $\beta$ (Vasko et al. 2007, Riesco-Eizaguirre et al. 2009, Eloy et al. 2012). Interestingly, while this high TGF $\beta / S M A D$ activity is predominant in the invasive front of the tumors, NIS is preferentially expressed in the central regions, suggesting that this negative correlation between TGF $\beta$ and NIS occurs locally inside the tumor (RiescoEizaguirre et al. 2009) (Fig. 2C). BRAF induces a TGF $\beta$ autocrine loop which downregulates PAX8 and evokes a SMAD3-dependent inhibition of PAX8 binding to the Nis promoter (Costamagna et al. 2004, Riesco-Eizaguirre et al. 2009) (Fig. 2B). In addition, BRAF-induced TGF $\beta 1$ induces large amounts of ROS through NOX4, a NADPH oxidase highly expressed in thyroid cancer, and such TGF $\beta$-induced ROS has been shown to repress NIS (Azouzi et al. 2017). Finally, two other considerations are worth to be noted. First, TGF $\beta$ delocalizes NIS from the plasma membrane altering its trafficking to the membrane through a yet unknown mechanism (Costamagna E, Riesco-Eizaguirre G \& Santisteban P, unpublished observations) (Fig. 2B). Secondly, cells in the tumor microenvironment other than BRAFV600E_PTC cells also contribute to the intratumoral pool of TGF $\beta$ and activin, including tumor-associated macrophages and other still unknown cells (Fig. 2A); thus, targeting TGF $\beta / S M A D$ would also block the inhibitory effects exerted by tumor microenvironment.

Several TGF $\beta$ signaling inhibitors have been shown to reinduce iodide uptake in PCCL3 cells expressing BRAF or RET/PTC, including small kinase inhibitors of T $\beta R I$ and a natural TGF $\beta 1$ inhibitor, apigenin (RiescoEizaguirre et al. 2009, Lakshmanan et al. 2015b). A very recent work in BRAFV600E-induced thyroid cancer in mice has demonstrated that vactosertib, a potent inhibitor of SMAD, was not able to restore expression of NIS or iodide uptake alone, yet the combination of either vactosertib or follistatin (a potent inhibitor of activin) and CKI (a MEK inhibitor) increased iodide uptake compared to CKI alone (Luckett et al. 2021). All these findings in cell lines and animal models indicate that these two pathways closely converge in the repression of NIS and iodide uptake in thyroid cancer cells (Fig. 2). The precise mechanism underlying the additive effect of SMAD and MEKinhibition on iodide uptake remains to be fully explored.

Clinical trials looking into synergistic effects of blocking SMAD and MAPK pathways in thyroid cancer look promising and are yet to be explored. Because TGF $\beta$ has also profound local immunosuppressive and immunoexclusion effects in the tumor microenvironment that are integrally involved in the failure of immune checkpoint inhibitors in some tumors, there are currently 
phase II clinical trials testing TGF $\beta$ inhibitors in refractory advanced and metastatic malignancies (NCT03834662). However, TGF $\beta$ acts as a tumor suppressor in normal tissues and early stages of cancer, making inhibition of TGF $\beta$ signaling challenging due to unwanted side effects. Therefore, blocking SMAD and MAPK pathways in thyroid cancer patients for short intervals followed by radioiodide treatment could be a reasonable strategy to limit drug toxicity (Huynh et al. 2019).

\section{PI3K signaling pathway and others}

PI3K/AKT signaling pathway plays an important role in tumor initiation and progression of thyroid cancer and has been shown to repress NIS and other iodide-metabolizing genes (Hou et al. 2010, Xing 2010). As mentioned earlier, in normal thyroid cells, IGF1 represses NIS transcriptional activity through PI3K/Akt signaling in TSH stimulated cells (García \& Santisteban 2002), and high levels of TSH also stimulates AKT phosphorylation through G $\beta \gamma$ dimers released from $G$ protein coupled to the TSHR, restraining cAMP-induced NIS expression (Zaballos et al. 2008). Thus, in normal thyroid cells, the PI3K/Akt pathway counterbalances the stimulatory effects of TSH.

Pharmacological inhibition of the PI3K pathway increases functional NIS expression in rat thyroid cells and human papillary thyroid cancer cells by several mechanisms, including posttranslational modifications (Kogai et al. 2008, Liu et al. 2012). Inhibitors for PI3K, AKT, or mTORC1 increase iodide uptake in thyroid PCCL3 cells under chronic TSH stimulation. However, although AKT inhibition increases NIS-mediated radioiodide uptake, it does not increase NIS protein levels (Liu et al. 2012). The authors suggest that this signaling pathway is promoting a posttranslational modification of NIS, that is, a change in its phosphorylation status, yet it is still a hypothesis that needs further confirmation. In addition, activation of PI3K/AKT signaling through MTOR leads to significant repression of iodide uptake (Plantinga et al. 2014, Tavares et al. 2018). Therefore, several inhibitors of this pathway have been proved to reinduce NIS expression and/or 131 I uptake (Hou et al. 2010). However, while the evidence targeting MAPK signaling pathway has been shown to be successful in cell lines, mice and humans, evidence targeting PI3K pathway is restricted to cell models.

Other pathways such as the NOTCH signaling pathway have been linked to the regulation of NIS and other thyroid-specific gene expression. Pharmacological Notch1 activating compounds such as resveratrol (Yu et al. 2013) or hesperetin (Patel et al. 2014) have been shown to induce
NIS mRNA levels and other differentiation markers in vitro in ATC cell lines. Interestingly, other compounds such as the HDAC inhibitors valproic acid and SAHA or retinoic acid have also been reported to activate Notch signaling (Xiao et al. 2009) .

\section{Trafficking to the membrane}

NIS needs to be targeted to the basolateral plasma membrane to actively transport iodide (Fig. 3). The trafficking of NIS to the membrane seems to be a process finely regulated by TSH (Riedel et al. 2001). Deprivation of TSH results in the reduction of NIS protein half-life from 5 to 3 days and redistribution of NIS protein from the cell surface to intracellular compartments. In a similar way, BRAFV600E redistributes NIS protein from the cell surface to intracellular compartments when it is conditionally induced in thyroid cells (Riesco-Eizaguirre et al. 2006). BRAFV600E impairs TSH/cAMP signaling and also induces TGF $\beta$ secretion, a strong NIS inhibitor which not only represses NIS transcriptionally (Riesco-Eizaguirre et al. 2009) but also alters its trafficking (Costamagna E, RiescoEizaguirre G \& Santisteban P, unpublished observations) (Fig. 2). Understanding how such important physiological and oncogenic events mediated by TSH and BRAF, respectively, affect NIS trafficking at a molecular level is clinically very relevant. In many human thyroid and breast cancers, NIS is still expressed or even overexpressed (Fig. 4), but unable to transport iodide because it is mainly localized in the cytoplasm (Wapnir et al. 2004). Therefore, targeting NIS transcriptional re-expression is undoubtedly a necessary step but not enough to render an active protein at the membrane.

The mechanisms governing NIS subcellular trafficking remain largely unknown, yet there have been some advances summarized in Fig. 3. The first attempts to elucidate the mechanisms involved in NIS trafficking focused on the posttranslational modifications of the protein, mainly glycosylation and phosphorylation. NIS is a highly glycosylated protein; there are three $\mathrm{N}$-linked glycosylation sites in the mature form of NIS. Using site-directed mutagenesis in NIS-expressing COS cells, Carrasco's group demonstrated that glycosylation affects the function and stability of NIS to a certain extent, but the partial or total absence of N-linked glycosylation did not dampen much NIS activity, ranging from 90 to 50\%, respectively (Levy et al. 1998). Further studies in thyroid and breast cancer cells using different glycosylation inhibitors have shown that alteration in the glycosylation 


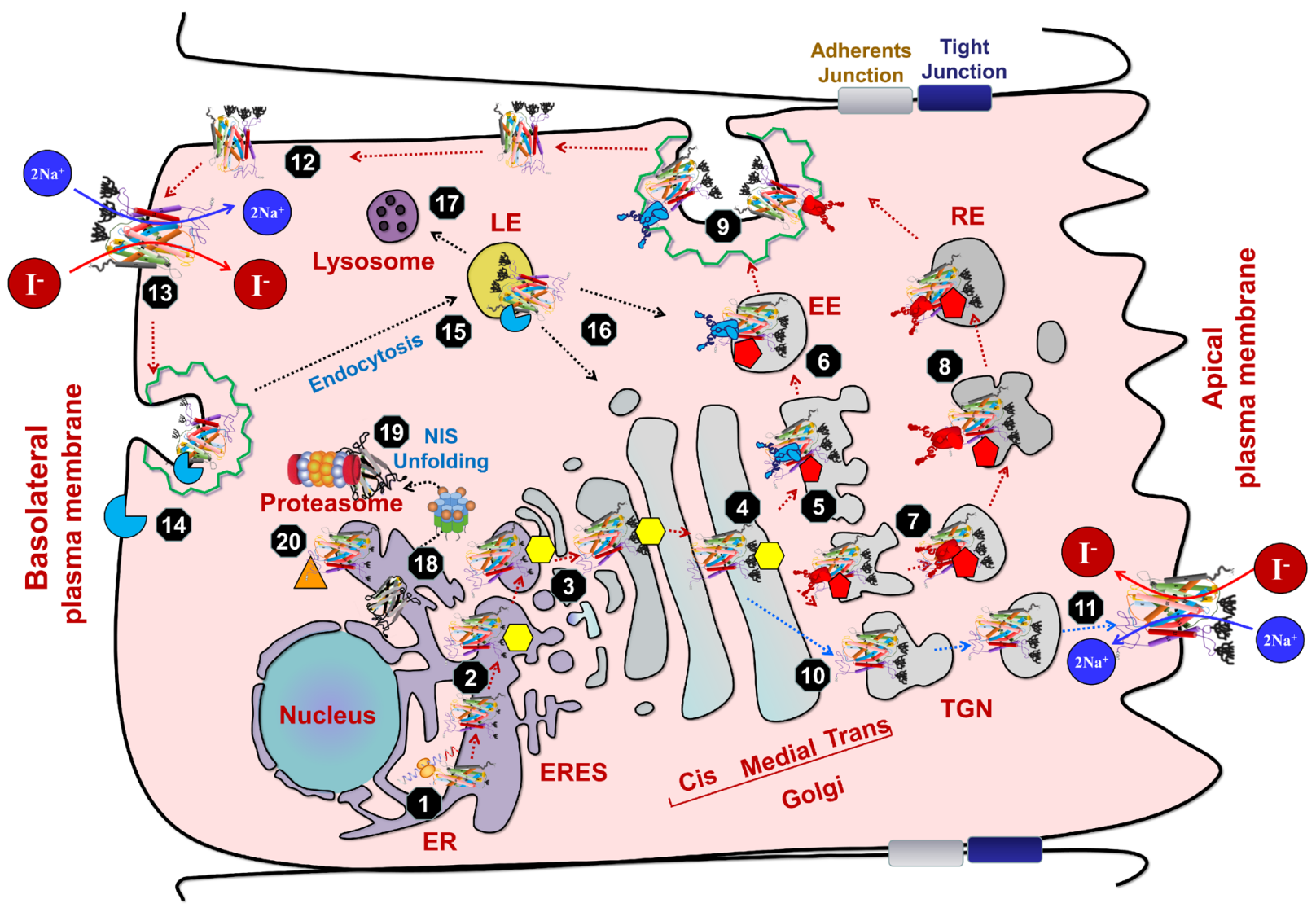

$\begin{array}{lll}\text { NIS partially synthesis } & \text { Partially glycosylated NIS } & \text { MAN1A1, MAN1B1 } \\ \text { and MAN2A1 }\end{array}$

\section{Figure 3}

Mechanism of synthesis, PTM, trafficking, and degradation of NIS in thyroid and extra-thyroid. After ribosomal protein biosynthesis (1), NIS folding and $\mathrm{N}$-glycosylation processes start at the ER (2). PIGU, a protein that catalyzes glycosylphosphatidylinositol in the ER, may be involved in NIS glycosylation process. This protein is regulated by MAPK signaling. Several enzymes are implicated in $\mathrm{N}$-glycans protein processing. Three mannosidase enzymes (Man1a1, Ma1b1, and Man2a1) participate in NIS N-glycosylation at the GGolgi (3-4). General alteration of glycosylation in cells affects NIS trafficking. Specifically, alteration in expression levels or function of these mannosidases causes defective NIS glycosylation that affects NIS maturation and accumulation in cytoplasm organelles. Final maturation of glycosylation occurs in the trans GGolgi $(4)$. Then, AP-1A $(5,6)$ and AP1B $(7,8)$ clathrin adaptor proteins are implicated in NIS trafficking from GGolgi to the basolateral plasma membrane (9). Interaction of the AP-1B subunit $\sigma 1$ with an IL motif at NIS C-terminal is important for correct basolateral trafficking in epithelial cells. In the absence of AP-1 clathrin adaptors, as in kidney, small intestine, duodenum, colon, and cytotrophoblasts in placenta cells, NIS traffics to the apical plasma membrane (10-11). ARF4 binding to the VAPK motif in NIS participated in NIS trafficking from GGolgi to the plasma membrane $(5-8)$. NIS is distributed throughout the plasma membrane $(9,12)$ where it exerts its iodide sodium-dependent function (13). NIS half-life at the plasma membrane is around 5 days. After this, NIS endocytosis begins. PBF is known to participate in the endocytic pathway of NIS (14). Phosphorylated PBF at residue Y174 causes NIS internalization from plasma membrane to cytoplasm in a clathrin-dependent endocytosis. Then, NIS in the LE can be recycled to the ER, LE, or RE (16) and back to the plasma membrane, or go to lysosome for degradation (17). VCP participates in NIS degradation at the ER through the proteasome (19). In addition, unfolded or cytoplasmic retained NIS (18) go to proteasome degradation (19). LARG interaction with the C-terminal PDZ motif of NIS causes NIS cytoplasm retention (20), which increases cell motility and invasion in tumor cells. This interaction is, at least in part, mediated by PTEN alteration. Nomenclature: (A) proteins: ARF4, ADP-ribosylation factor 4; LARG, leukemia-associated RhoA guanine exchange factor; PBF, pituitary tumor-transforming gene I binding factor; VCP, valosin-containing protein; PIGU, phosphatidylinositol glycan anchor biosynthesis class U; (B) subcellular organelles: ER, endoplasmic reticulum; ERES, ER export sites; EE, early endosome; $R E$, recycling endosome; LE, late endosome; TGN, trans-GGolgi network. 
A

\begin{tabular}{|c|c|c|c|c|c|c|}
\hline \multirow[b]{2}{*}{ Type of Cancer } & \multicolumn{4}{|c|}{ NIS Protein level } & \multicolumn{2}{|c|}{ SLC5A5 mRNA level } \\
\hline & $\begin{array}{c}\text { Protein } \\
\text { Expression } \\
\text { Tumor vs. } \\
\text { Normal tissue }\end{array}$ & $\begin{array}{l}\text { \% NIS positive } \\
\text { staining }\end{array}$ & $\begin{array}{l}\text { \% cells with some } \\
\text { PM staining }\end{array}$ & $\begin{array}{l}\text { Are some of the } \\
\text { metastatic tissue } \\
\text { positive? }\end{array}$ & $\begin{array}{c}\text { mRNA } \\
\text { Expression } \\
\text { Tumor vs. } \\
\text { Normal tissue } \\
\end{array}$ & $\begin{array}{c}\text { fold } \\
\text { [increase } \\
\text { or } \\
\text { decrease] }\end{array}$ \\
\hline Bladder & $V$ & 42 & & & $\Delta$ & 3.5 \\
\hline Breast & $\Delta$ & 80 & 24 & Yes & $\hat{\mathrm{S}}$ & 2.3 \\
\hline Cervix & $\Delta$ & 100 & & & 令 & 1.4 \\
\hline Colon & 焉 & 63 & & & 垔 & 1.0 \\
\hline Endometrial & $\Delta$ & 56 & & & & 8.0 \\
\hline Esophagus & S & 47 & & & $>$ & 5.3 \\
\hline Gastric & 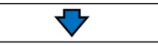 & 59 & & & & -10.0 \\
\hline Kidney & 5 & 29 & & & $\hat{\mathrm{S}}$ & 2.0 \\
\hline Liver $^{*}$ & & 20 & & & 昰 & 1.1 \\
\hline Lung & 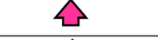 & 66 & & & $\Delta$ & 1.5 \\
\hline Melanoma & $\Delta$ & 33 & & & 牲 & 1.0 \\
\hline Ovarian & $\widehat{s}$ & 95 & 33 & & $\widehat{O r}$ & 10.0 \\
\hline Pancreas & $\nabla$ & 64 & & & 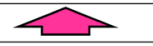 & 7.5 \\
\hline Prostate & 5 & 74 & & & 令 & 1.4 \\
\hline Salivary & 5 & 32 & & & 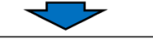 & -7.0 \\
\hline Skin squamous & $\Delta$ & 56 & & & 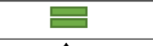 & 1.0 \\
\hline Testicular & $\Delta$ & 76 & & & $\hat{\mathrm{S}}$ & 2.6 \\
\hline Thymus & $\Delta$ & 100 & & & 焉 & 1.2 \\
\hline Thyroid & $\sqrt{2}$ & 73 & & Yes & 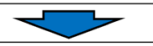 & -10.0 \\
\hline
\end{tabular}

B

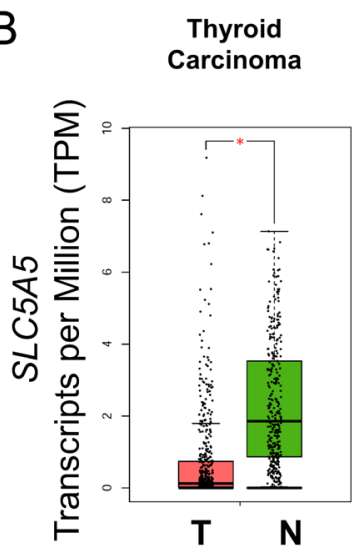

Stomach
adenocarcinoma

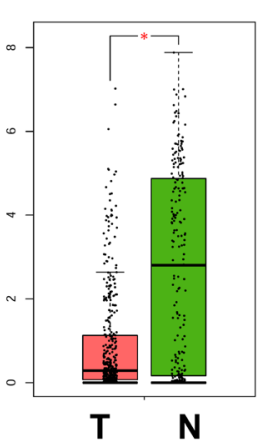

Breast Invasive carcinoma

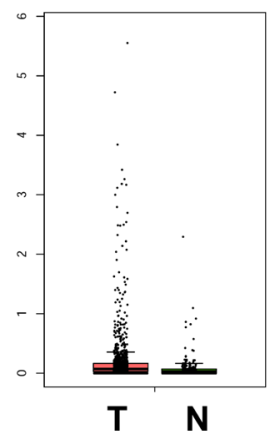

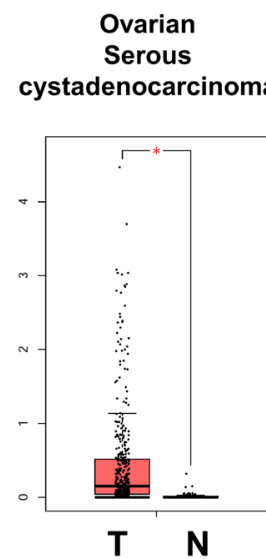

Ovarian

Testicular

Germ Cell

Tumors

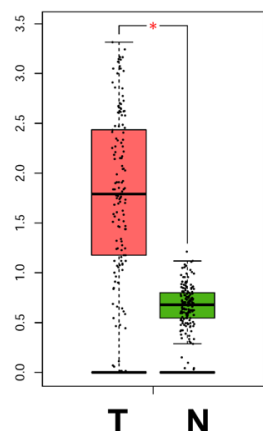

\section{Figure 4}

NIS expression regulation in tumors is tissue-dependent. (A) Levels of NIS protein and mRNA expression in tumors vs normal tissue. Relative protein levels were obtained in several studies by tissue-array. In addition, \% of NIS-expressing positive cells within the tumors, \% of cells expressing NIS at the plasma membrane, and metastatic cells expressing NIS are indicated. mRNA levels in tumor vs normal tissue are obtained in the GEPIA (gene expression profiling interactive analysis) portal. (B) Variation of NIS expression in five relevant tumors ( $\mathrm{T}$, red colors) vs normal tissue (N, green colors) is represented in box-blot. Data obtained in GEPIA portal. Normalization of RNA-seq data is represented as transcripts per million (TPM).

process affects NIS trafficking to the membrane (Beyer et al. 2011, Chung et al. 2015, Feng et al. 2018). However, because these inhibitors also inhibit the glycosylation of many other proteins, the specific role of NIS glycosylation is unclear. Recently, three mannosidases (MAN1A1, MAN1B1, and MAN2A1) have been proposed to be implicated specifically in NIS glycosylation (Rathod et al. 2019). These enzymes are likely able to condition the degree of NIS glycosylation in different tissues and tumors, making NIS have different molecular weights in the thyroid (see 'Trafficking to the membrane' section and Table 1) (De la Vieja et al. 2000, Riesco-Eizaguirre et al. 2014). NIS is also a phosphoprotein and the carboxy terminus, where most of the phosphorylation occurs under the regulation of TSH, was initially proposed to have a role in NIS trafficking and its localization at the basolateral 
plasma membrane (Riedel et al. 2001). Notwithstanding, using site-directed mutagenesis, the phosphorylation status of several aa residues, including those in the carboxy terminus, do not seem to affect NIS cell surface trafficking (Vadysirisack et al. 2007). Recent evidence has shown that a conserved monoleucine-based motif at the carboxy terminus influences the trafficking route of NIS to the basolateral or the apical membrane in polarized epithelial cells (Koumarianou et al. 2014, Martín et al. 2019). The interaction of such motif with the clathrin adaptor protein AP-1B subunit $\sigma 1$ serves as a sorting signal that allows for the correct trafficking of NIS to the basolateral membrane, while the absence of AP-1 clathrin adaptors makes NIS traffic to the apical membrane (Fig. 3).

In recent years, some proteins have been identified to interact with NIS and modulate its subcellular localization (Fig. 3). The first protein shown to bind NIS and affect its trafficking was PBF (pituitary tumor-transforming gene (PTTG1)-binding factor). As mentioned in 'Promoters and enhancers regulating NIS transcription' section, this proto-oncogene acts mainly at the cell nucleus along with PTTG1 driving thyroid tumorigenesis via different mechanisms and repressing NIS transcription through USF1 (Stratford et al. 2005, Boelaert et al. 2007). However, PBF has been shown to act independently of PTTG and out of the nucleus, predominantly within intracellular vesicles and at the plasma membrane (Smith et al. 2009, 2011). It has a functional endocytosis motif that binds NIS and redistributes NIS away from the plasma membrane into late endosomes, particularly into clathrin-coated CD63positive late endosomes, resulting in significantly repressed cellular iodide uptake (Fig. 3) (Smith et al. 2009). Evidence of PBF's role in thyroid tumorigenesis is supported by the high levels of this protein found in human thyroid cancer, particularly in the most aggressive tumors that are refractory to radioactive iodide and by transgenic mice in which targeted overexpression of PBF induces thyroid hyperplasia and goiter (Read et al. 2011).

Apart from NIS regulation through an endocytosismediated pathway, very recently two other proteins have been shown to participate in NIS trafficking at other levels both in breast and thyroid cancer models. McCabe's group have identified that ADP ribosylation factor 4 (ARF4) and valosin-containing protein (VCP) specifically bind NIS and regulate its trafficking or retention at the plasma membrane (Fletcher et al. 2020). ARF4 is a small GTPase that functions in trans-GGolgi network sorting of certain proteins into carrier vesicles. ARF4 binds to the carboxy terminus of NIS and potentiates its function by promoting its trafficking through vesicles destined to the plasma membrane. On the other hand, VCP is a chaperone that dissembles protein complexes and facilitates proteasomal degradation of proteins from the ER. VCP seems to promote dislocation of NIS from the ER and subsequent proteasome degradation. In contrast to ARF4 in which no current specific agonists exist, VCP is specifically druggable with FDA-approved inhibitors such as ebastine and clotrimazole, resulting in enhanced radioiodide uptake in thyroid cancer models. These two well-known drugs are well tolerated in vivo and look promising for future clinical trials in radioiodide-refractory thyroid cancer patients, most likely in combination with other redifferentiation strategies.

In another interesting work, the same group performed a high throughput screening for $~ 1200$ FDA-approved drugs to see the most effective drug in reinducing ${ }^{125}$ I uptake in a thyroid cancer cell model (Read et al. 2020). Of all the drugs, the most effective were ebastine, clotrimazole, disulfiram, and SAHA. The combination of ebastine (a VCP inhibitor) and SAHA (a HDAC inhibitor) was the most effective. It is interesting to note that among those drugs, MEK and BRAF inhibitors (i.e. selumetinib), alone or in combination, were not as effective. In addition, based on the drug's mechanisms of action, they figured out a hypothetical model of NIS intracellular processing in which some steps can be clearly druggable. According to their in vitro model, targeting trafficking (i.e. blocking ER-associated proteasomal degradation) and epigenetic mechanisms (i.e. HDAC inhibition) would be most effective.

Overall, in very recent years, some interesting mechanisms have been unveiled to understand the trafficking of NIS to the plasma membrane (Fig. 3). The fact that many tumors express or even overexpress NIS in the cytoplasm but not in the membrane showcases that reinducing radioiodide uptake is not only a matter of enhancing NIS expression. NIS needs to be correctly localized at the plasma membrane, and combining different drugs that target both expression and localization seems most appropriate.

\section{NIS in extrathyroidal tissues, increasing the complexity}

NIS expression does not only occur in the thyroid gland. Before NIS was identified, numerous tissues were known to be capable of accumulating I- (Wolff 1964). After NIS was cloned in the thyroid (Dai et al. 1996), several
(C) 2021 Society for Endocrinology Published by Bioscientifica Ltd. Printed in Great Britain 
tissues containing NIS transcript were identified and characterized at genomic and protein levels. In some cases, NIS precise cellular and subcellular localization have been determined, as well as its functional level in other cases (Table 1) (Dohán et al. 2003, Ravera et al. 2017, De la Vieja \& Santisteban 2018).

NIS extra-thyroidal expression, regulation, function, subcellular localization, glycosylation level depend on each tissue (detailed summary in Table 1) and on the Ineeds/content (De la Vieja \& Santisteban 2018). In many cases, it has been demonstrated that extra-thyroidal NIS participates in functions such as: (1) collect, recycle, and retain as much $\mathrm{I}^{-}$as possible either from the diet, recycling of secondary metabolism, or the reabsorptions from urine, and thus pass I- into the blood so that it reaches the thyroid; (2) provide I- to the fetus and newborn so that they can synthesize their own TH; (3) provide I- that exerts an antioxidant role, reducing ROS levels by being easily oxidized; (4) provide I- to perform a powerful antimicrobial and antiviral protective role when oxidized to hypoiodite $\left(\mathrm{IO}^{-}\right)$(Kussendrager \& van Hooijdonk 2000) (De la Vieja \& Santisteban 2018). Hence, it seems that NIS expression is more ubiquitous than initially expected. Further work will reveal the precise role of NIS in each tissue.

NIS tumoral expression in extrathyroidal tissues has also acquired much notoriety and has opened the door to propose NIS as a theranostic agent, meaning both a prognostic/diagnostic marker and a therapeutic tool through the use of radioiodide in those endogenously NISexpressing tumors in a similar way to how it is performed in thyroid cancer. However, tumor progression and/or microenvironment affects NIS expression differently depending on the tissue. In some cases, as in the thyroid, the expression of NIS is downregulated or overexpressed (Fig. 4) (Wapnir et al. 2003, Altorjay et al. 2007, la Perle et al. 2013). More importantly, in some tumors, NIS is present at the plasma membrane and, therefore, target to radioiodide therapy (Tazebay et al. 2000, Liu et al. 2007b, RiescoEizaguirre et al. 2014, Shiozaki et al. 2019). On the other hand, recent work in cancer and metastases has also shown that cytoplasmic/intracellularly retained NIS triggers strong oncogenic effects via interactions with leukemiaassociated RhoA guanine exchange factor (LARG) (Lacoste et al. 2012) that seems to be facilitated by the PI3K/AKT/ mTOR signaling pathway (Feng et al. 2018). This metastatic potential may be another reason to redirect intracellular NIS to the plasma membrane. It would not only render tumors amenable to ${ }^{131}$ I radiotherapy but could have the additional positive effect of slowing tumor progression.

\section{Concluding remarks and perspectives}

NIS increasing complexity is a challenge and at the same time an opportunity to extend its clinical applications. Significant progress has been made in understanding NIS regulation at different levels and in different tissues.

NIS transcription is under the control of different transcriptional regulatory elements in a tissue-depending manner to regulate temporal and spatial NIS expression. NIS in the thyroid gland depends largely on a distant upstream enhancer activity (i.e. NUE) mediated by TSH/cAMP stimulation that acts through a synergism between PAX8 and CRE-like binding factors, whereas NIS in the mammary gland depends primarily on the proximal promoter through the synergism of NKX2.5 and ER $\alpha$ enhanced by RA stimulation through intronic regulatory elements and other lactogenic hormones. Presumably, other transcriptional regulatory elements may emerge in the future through genome-wide approaches to understand the regulation of NIS in other hormonally regulated tissues.

NIS posttranscriptional regulation by miRNAs most likely depends on the co-regulation between miRNA and transcription factors, forming auto-regulatory network motifs including direct reciprocal feedback loops and feedforward loops. A prominent example is miR-146-3p and PAX8 and their shared target NIS. Other miRNAtranscription factors pairs of regulation might be operating to modulate NIS and other iodide-metabolizing genes.

Aberrant signaling pathways and impaired trafficking to the membrane are two major mechanisms underlying NIS dysregulation in cancer in which significant progress has been made. On the one hand, there is an exquisite dependence of NIS repression on the activity of MAPK signaling pathway that acts through the locally secreted cytokine TGFbeta. Indeed, MAPK inhibitors have reached clinical trials with partial success in thyroid cancer patients. The synergistic effects of blocking SMAD and MAPK pathways observed in cell lines and animal models look promising and are yet to be explored in humans. Other signaling pathways, prominent in some types of thyroid cancer (e.g. PI3K), are also to be considered. On the other hand, new insights into the route that NIS follows through different subcellular compartments have shown us druggable ways to relocalize NIS to the membrane and enhance ioidide uptake (e.g. through inhibition of ER-proteasomal degradation). Combining therapies targeting both NIS re-expression and re-localization to the plasma membrane looks like a plausible way to reinduce 
radioiodide uptake and extend the benefits of treatment to more patients with refractory thyroid cancer.

Unveiling NIS function in extrathyroidal tissues is an emerging field relatively unexplored. NIS does not only provide iodide to assure the synthesis of thyroid hormones but most likely provides iodide that has a protective role in tissues most exposed to external microorganisms. NIS takes part in the peroxidase system allowing cells to generate hypoiodite $\left(\mathrm{IO}^{-}\right)$, a strong oxidizing element that functions as an antimicrobial agent. Finally, we now know that NIS is not merely a supporting actor during tumor transformation. In fact, NIS is overexpressed and associated with worse clinical outcomes in some types of cancer. Intracellular NIS functions as an important mediator of signaling pathways promoting tumor transformation and progression, where the C-terminus plays an essential role in being independent of the symporter transport activity. This novel oncogenic function may serve as a cautionary note on re-expressing NIS artificially in cancer cells, particularly if is not expressed in the membrane.

\section{Declaration of interest}

The authors declare that there is no conflict of interest that could be perceived as prejudicing the impartiality of this review.

\section{Funding}

The authors want to thank the support of the following Grants: PID2019105303RB-I00/AEI/10.13039/501100011033 from MICIN and B2017/BMD3724 Tironet2 from Comunidad de Madrid (to P S); MICIU/FEDER RTI2018099343-B-100 (to A D I V). The Asociación Española Contra el Cancer (AECC); GCB141423113) jointly awarded to P S and G R-E. PS, G R-E, and A D I V, belong to CIBERONC ISCIII.

\section{Acknowledgement}

The authors thank Monica Torres-Ruiz for her assistance with the correct use of English.

\section{References}

Ajjan RA, Watson PF, Findlay C, Metcalfe RA, Crisp M, Ludgate M \& Weetman AP 1998 The sodium iodide symporter gene and its regulation by cytokines found in autoimmmunity. Journal of Endocrinology 158 351-358. (https://doi.org/10.1677/ joe.0.1580351)

Agrawal N, Akbani R, Aksoy BA, Ally A, Arachchi H, Asa SL, Auman JT, Balasundaram M, Balu S, Baylin SB, et al. 2014 Integrated genomic characterization of papillary thyroid carcinoma. Cell 159 676-690. (https://doi.org/10.1016/j.cell.2014.09.050)

Alotaibi H, Yaman EC, Demirpençe E \& Tazebay UH 2006 Unliganded estrogen receptor- $\alpha$ activates transcription of the mammary gland $\mathrm{Na}+/ \mathrm{I}-$ symporter gene. Biochemical and Biophysical Research
Communications 345 1487-1496. (https://doi.org/10.1016/j. bbrc.2006.05.049)

Alotaibi H, Yaman E, Salvatore D, di Dato V, Telkoparan P, di Lauro R \& Tazebay UH 2010 Intronic elements in the Na+/I- symporter gene (NIS) interact with retinoic acid receptors and mediate initiation of transcription. Nucleic Acids Research 38 3172-3185. (https://doi. org/10.1093/nar/gkq023)

Alotaibi H, Tuzlakoğlu-Öztürk M \& Tazebay UH 2017 The thyroid Na+/Isymporter: molecular characterization and genomic regulation. Molecular Imaging and Radionuclide Therapy 26 92-101. (https://doi. org/10.4274/2017.26.suppl.11)

Altorjay A, Dohán O, Szilágyi A, Paroder M, Wapnir IL \& Carrasco N 2007 Expression of the Na+/I- symporter (NIS) is markedly decreased or absent in gastric cancer and intestinal metaplastic mucosa of Barrett esophagus. BMC Cancer 7 5. (https://doi.org/10.1186/1471-2407-7-5)

Amiri-Kordestani L, Luchenko V, Peer CJ, Ghafourian K, Reynolds J, Draper D, Frye R, Woo S, Venzon D, Wright J, et al. 2013 Phase I trial of a new schedule of romidepsin in patients with advanced cancers. Clinical Cancer Research 19 4499-4507. (https://doi.org/10.1158/1078-0432.CCR-13-0095)

Andersson R \& Sandelin A 2020 Determinants of enhancer and promoter activities of regulatory elements. Nature Reviews: Genetics 21 71-87. (https://doi.org/10.1038/s41576-019-0173-8)

Arriagada AA, Albornoz E, Opazo MC, Becerra A, Vidal G, Fardella C, Michea L, Carrasco N, Simon F, Elorza AA, et al. 2015 Excess iodide induces an acute inhibition of the sodium/iodide symporter in thyroid male rat cells by increasing reactive oxygen species. Endocrinology 156 1540-1551. (https://doi.org/10.1210/en.2014-1371)

Azouzi N, Cailloux J, Cazarin JM, Knauf JA, Cracchiolo J, al Ghuzlan A, Hartl D, Polak M, Carré A, el Mzibri M, et al. 2017 NADPH oxidase NOX4 is a critical mediator of BRAFV600E-induced downregulation of the sodium/iodide symporter in papillary thyroid carcinomas. Antioxidants and Redox Signaling 26 864-877. (https://doi.org/10.1089/ ars.2015.6616)

Beyer S, Lakshmanan A, Liu YY, Zhang X, Wapnir I, Smolenski A \& Jhiang S 2011 KT5823 differentially modulates sodium iodide symporter expression, activity, and glycosylation between thyroid and breast cancer cells. Endocrinology 152 782-792. (https://doi. org/10.1210/en.2010-0782)

Boelaert K, Smith VE, Stratford AL, Kogai T, Tannahill LA, Watkinson JC, Eggo MC, Franklyn JA \& McCabe CJ 2007 PTTG and PBF repress the human sodium iodide symporter. Oncogene 26 4344-4356. (https:// doi.org/10.1038/sj.onc.1210221)

Bollag G, Hirth P, Tsai J, Zhang J, Ibrahim PN, Cho H, Spevak W, Zhang C, Zhang Y, Habets G, et al. 2010 Clinical efficacy of a RAF inhibitor needs broad target blockade in BRAF-mutant melanoma. Nature $\mathbf{4 6 7}$ 596-599. (https://doi.org/10.1038/nature09454)

Bracken CP, Scott HS \& Goodall GJ 2016 A network-biology perspective of microRNA function and dysfunction in cancer. Nature Reviews: Genetics 17 719-732. (https://doi.org/10.1038/nrg.2016.134)

Braverman LE \& Ingbar SH 1963 Changes in thyroidal function during adaptation to large doses of iodide. Journal of Clinical Investigation $\mathbf{4 2}$ 1216-1231. (https://doi.org/10.1172/JCI104807)

Buffet C, Wassermann J, Hecht F, Leenhardt L, Dupuy C, Groussin L \& Lussey-Lepoutre C 2020 Redifferentiation of radioiodine-refractory thyroid cancers. Endocrine-Related Cancer 27 R113-R132. (https://doi. org/10.1530/ERC-19-0491)

Chakravarty D, Santos E, Ryder M, Knauf JA, Liao XH, West BL, Bollag G, Kolesnick R, Thin TH, Rosen N, et al. 2011 Small-molecule MAPK inhibitors restore radioiodine incorporation in mouse thyroid cancers with conditional BRAF activation. Journal of Clinical Investigation 121 4700-4711. (https://doi.org/10.1172/JCI46382)

Chin HS, Chin DKH, Morgenthaler NG, Vassart G \& Costagliol S 2000 Rarity of anti- Na+/I- symporter (NIS) antibody with iodide uptake inhibiting activity in autoimmune thyroid diseases (AITD). Journal of Clinical Endocrinology and Metabolism 85 3937-3940. (https://doi. org/10.1210/jcem.85.10.6884) 
Choi YW, Kim HJ, Kim YH, Park SH, Chwae YJ, Lee J, Soh EY, Kim JH \& Park TJ 2014 B-RafV600E inhibits sodium iodide symporter expression via regulation of DNA methyltransferase 1. Experimental and Molecular Medicine 46 e120. (https://doi.org/10.1038/emm.2014.68)

Chun JT \& di Lauro R 2001 Characterization of the upstream enhancer of the rat sodium/iodide symporter gene. Experimental and Clinical Endocrinology and Diabetes 109 23-26. (https://doi. org/10.1055/s-2001-11021)

Chun JT, di Dato V, D'Andrea B, Zannini M \& di Lauro R 2004 The CRElike element inside the $5^{\prime}$-upstream region of the rat sodium/iodide symporter gene interacts with diverse classes of b-zip molecules that regulate transcriptional activities through strong synergy with Pax-8. Molecular Endocrinology 18 2817-2829. (https://doi.org/10.1210/ me.2004-0020)

Chung T, Youn H, Yeom CJ, Kang KW \& Chung JK 2015 Glycosylation of sodium/iodide symporter (NIS) regulates its membrane translocation and radioiodine uptake. PLOS ONE 10 e0142984. (https://doi. org/10.1371/journal.pone.0142984)

Costamagna E, García B \& Santisteban P 2004 The functional interaction between the paired domain transcription factor Pax8 and Smad3 is involved in transforming growth factor- $\beta$ repression of the sodium/ iodide symporter gene. Journal of Biological Chemistry 279 3439-3446. (https://doi.org/10.1074/jbc.M307138200)

Dai G, Levy O \& Carrasco N 1996 Cloning and characterization of the thyroid iodide transporter. Nature 379 458-460. (https://doi. org/10.1038/379458a0)

De Felice M \& Di Lauro R 2004 Thyroid development and its disorders: genetics and molecular mechanisms. Endocrine Reviews 25 722-746. (https://doi.org/10.1210/er.2003-0028)

De la Vieja A \& Riesco-Eizaguirre G 2021 Radio-iodide treatment: from molecular aspects to the clinical view. Cancers 13 995. (https://doi. org/10.3390/cancers13050995)

De la Vieja A \& Santisteban P 2018 Role of iodide metabolism in physiology and cancer. Endocrine-Related Cancer 25 R225-R245. (https://doi.org/10.1530/ERC-17-0515)

De la Vieja A, Dohan O, Levy O \& Carrasco N 2000 Molecular analysis of the sodium/iodide symporter: impact on thyroid and extrathyroid pathophysiology. Physiological Reviews 80 1083-1105. (https://doi. org/10.1152/physrev.2000.80.3.1083)

De Vita G, Zannini M, Cirafici AM, Melillo RM, Lauro R di, Fusco A \& Santoro M 1998 Expression of the RET/PTC1 oncogene impairs the activity of TTF-1 and Pax-8 thyroid transcription factors. Cell Growth and Differentiation 9 97-103.

Dentice M, Luongo C, Elefante A, Romino R, Ambrosio R, Vitale M, Rossi G, Fenzi G \& Salvatore D 2004 Transcription factor Nkx-2.5 induces sodium/iodide symporter gene expression and participates in retinoic acid- and lactation-induced transcription in mammary cells. Molecular and Cellular Biology 24 7863-7877. (https://doi.org/10.1128/ MCB.24.18.7863-7877.2004)

Dentice M, Cordeddu V, Rosica A, Ferrara AM, Santarpia L, Salvatore D, Chiovato L, Perri A, Moschini L, Fazzini C, et al. 2006 Missense mutation in the transcription factor NKX2-5: a novel molecular event in the pathogenesis of thyroid dysgenesis. Journal of Clinical Endocrinology and Metabolism 91 1428-1433. (https://doi.org/10.1210/jc.2005-1350)

Dohán O, de la Vieja A, Paroder V, Riedel C, Artani M, Reed M, Ginter CS \& Carrasco N 2003 The sodium/iodide symporter (NIS): characterization, regulation, and medical significance. Endocrine Reviews 24 48-77. (https://doi.org/10.1210/er.2001-0029)

Dohán O, de La Vieja A \& Carrasco N 2006 Hydrocortisone and purinergic signaling stimulate sodium/iodide symporter (NIS)-mediated iodide transport in breast cancer cells. Molecular Endocrinology 20 1121-1137. (https://doi.org/10.1210/me.2005-0376)

Eloy C, Santos J, Cameselle-Teijeiro J, Soares P \& Sobrinho-Simões M 2012 TGF-beta/Smad pathway and BRAF mutation play different roles in circumscribed and infiltrative papillary thyroid carcinoma. Virchows Archiv 460 587-600. (https://doi.org/10.1007/s00428-012-1234-y)
Endo T, Kaneshige M, Nakazato M, Ohmori M, Harii N \& Onaya T 1997 Thyroid transcription factor-1 activates the promoter activity of rat thyroid Na/I symporter gene. Molecular Endocrinology 11 1747-1755. (https://doi.org/10.1210/mend.11.11.0012)

Eng PHK, Cardona GR, Fang SL, Previti M, Alex S, Carrasco N, Chin WW \& Braverman LE 1999 Escape from the acute Wolff-Chaikoff effect is associated with a decrease in thyroid sodium/iodide symporter messenger ribonucleic acid and protein. Endocrinology $1403404-3410$. (https://doi.org/10.1210/endo.140.8.6893)

Eng PHK, Cardona GR, Previti MC, Chin WW \& Braverman LE 2001 Regulation of the sodium iodide symporter by iodide in FRTL-5 cells. European Journal of Endocrinology 144 139-144. (https://doi. org/10.1530/eje.0.1440139)

Faria M, Domingues R, Paixão F, Bugalho MJ, Matos P \& Silva AL 2020 $\mathrm{TNF} \alpha$-mediated activation of NF- $\kappa \mathrm{B}$ downregulates sodium-iodide symporter expression in thyroid cells. PLOS ONE 15 e0228794. (https:// doi.org/10.1371/journal.pone.0228794)

Feng F, Yehia L, Ni Y, Chang YS, Jhiang SM \& Eng C 2018 A nonpump function of sodium iodide symporter in thyroid cancer via cross-talk with PTEN signaling. Cancer Research 78 6121-6133. (https://doi. org/10.1158/0008-5472.CAN-18-1954)

Fenton MS, Marion KM \& Hershman JM 2008 Identification of cyclic adenosine $3^{\prime}, 5^{\prime}$-monophosphate response element modulator as an activator of the human sodium/iodide symporter upstream enhancer. Endocrinology 149 2592-2606. (https://doi.org/10.1210/en.2007-1390)

Fernández LP, López-Márquez A, Martínez AM, Gómez-López G \& Santisteban P 2013 New insights into FoxE1 functions: identification of direct FoxE1 targets in thyroid cells. PLoS ONE 8 e62849. (https:// doi.org/10.1371/journal.pone.0062849)

Fletcher A, Read ML, Thornton CEM, Larner DP, Poole VL, Brookes K, Nieto HR, Alshahrani M, Thompson RJ, Lavery GG, et al. 2020 Targeting novel sodium iodide symporter interactors ADP-ribosylation factor 4 and valosin-containing protein enhances radioiodine uptake. Cancer Research 80 102-115. (https://doi.org/10.1158/0008-5472.CAN-19-1957)

Furlanetto TW, Nguyen LQ \& Jameson JL 1999 Estradiol increases proliferation and down-regulates the sodium/iodide symporter gene in FRTL-5 cells. Endocrinology 140 5705-5711. (https://doi.org/10.1210/ endo.140.12.7197)

Fuziwara CS, Saito KC \& Kimura ET 2020 Thyroid follicular cell loss of differentiation induced by microRNA miR-17-92 cluster is attenuated by CRISPR/Cas9n gene silencing in anaplastic thyroid cancer. Thyroid 30 81-94. (https://doi.org/10.1089/thy.2018.0601)

Galrão AL, Camargo RY, Friguglietti CU, Moraes L, Cerutti JM, SerranoNascimento C, Suzuki MF, Medeiros-Neto G \& Rubio IGS 2014 Hypermethylation of a new distal sodium/iodide symporter (NIS) enhancer (NDE) is associated with reduced nis expression in thyroid tumors. Journal of Clinical Endocrinology and Metabolism 99 E944-E952. (https://doi.org/10.1210/jc.2013-1450)

García B \& Santisteban P 2002 PI3K is involved in the IGF-I inhibition of TSH-induced sodium/iodide symporter gene expression. Molecular Endocrinology 16 342-352. (https://doi.org/10.1210/mend.16.2.0774)

Giuliani C, Bucci I \& Napolitano G 2018 The role of the transcription factor nuclear factor-kappa B in thyroid autoimmunity and cancer. Frontiers in Endocrinology 9 471. (https://doi.org/10.3389/ fendo.2018.00471)

Gosline SJC, Gurtan AM, JnBaptiste CK, Bosson A, Milani P, Dalin S, Matthews BJ, Yap YS, Sharp PA \& Fraenkel E 2016 Elucidating microRNA regulatory networks using transcriptional, posttranscriptional, and histone modification measurements. Cell Reports 14 310-319. (https://doi.org/10.1016/j.celrep.2015.12.031)

Grollman EF, Smolar A, Ommaya A, Tombaccini D \& Santisteban P 1986 Iodine suppression of iodide uptake in frtl-5 thyroid cells. Endocrinology 118 2477-2482. (https://doi.org/10.1210/endo-118-6-2477)

Hertz B 2019 A tribute to Dr. Saul Hertz: the discovery of the medical uses of radioiodine. World Journal of Nuclear Medicine 18 8-12. (https://doi. org/10.4103/wjnm.WJNM_107_18) 
Hertz S \& Roberts A 1946 Radioactive iodine in the study of thyroid physiology; the use of radioactive iodine therapy in Graves' disease. Western Journal of Surgery, Obstetrics, and Gynecology $\mathbf{5 4} 474-486$.

Hertz S, Roberts A \& Salter WT 1942 Radioactive iodine as an indicator in thyroid physiology. IV. The metabolism of iodine in Graves' disease 1. Journal of Clinical Investigation 21 25-29. (https://doi.org/10.1172/ JCI101275)

Heufelder AE, Joba W \& Morgenthaler NG 2001 Autoimmunity involving the human sodium/iodide symporter: fact or fiction? Experimental and Clinical Endocrinology and Diabetes 109 35-40. (https://doi. org/10.1055/s-2001-11011)

Ho AL, Grewal RK, Leboeuf R, Sherman EJ, Pfister DG, Deandreis D, Pentlow KS, Zanzonico PB, Haque S, Gavane S, et al. 2013 Selumetinibenhanced radioiodine uptake in advanced thyroid cancer. New England Journal of Medicine 368 623-632. (https://doi.org/10.1056/ NEJMoa1209288)

Hou P, Bojdani E \& Xing M 2010 Induction of thyroid gene expression and radioiodine uptake in thyroid cancer cells by targeting major signaling pathways. Journal of Clinical Endocrinology and Metabolism 95 820-828. (https://doi.org/10.1210/jc.2009-1888)

Hou S, Xie X, Zhao J, Wu C, Li N, Meng Z, Cai C \& Tan J 2020 Downregulation of miR-146b-3p inhibits proliferation and migration and modulates the expression and location of sodium/iodide symporter in dedifferentiated thyroid cancer by potentially targeting MUC20. Frontiers in Oncology 10 566365. (https://doi.org/10.3389/ fonc.2020.566365)

Huc-Brandt S, Marcellin D, Graslin F, Averseng O, Bellanger L, Hivin P, Quemeneur E, Basquin C, Navarro V, Pourcher T, et al. 2011 Characterisation of the purified human sodium/iodide symporter reveals that the protein is mainly present in a dimeric form and permits the detailed study of a native C-terminal fragment. Biochimica et Biophysica Acta 1808 65-77. (https://doi.org/10.1016/j. bbamem.2010.08.013)

Huynh LK, Hipolito CJ \& ten P 2019 A perspective on the development of TGF- $\beta$ inhibitors for cancer treatment. Biomolecules 9 743. (https://doi. org/10.3390/biom9110743)

Kang HS, Kumar D, Liao G, Lichti-Kaiser K, Gerrish K, Liao XH, Refetoff S, Jothi R \& Jetten AM 2017 GLIS3 is indispensable for TSH/TSHRdependent thyroid hormone biosynthesis and follicular cell proliferation. Journal of Clinical Investigation 127 4326-4337. (https:// doi.org/10.1172/JCI94417)

Kawaguchi A, Ikeda M, Endo T, Kogai T, Miyazaki A \& Onaya T 1997 Transforming growth factor- $\beta 1$ suppresses thyrotropin-induced $\mathrm{Na}+/ \mathrm{I}-$ symporter messenger RNA and protein levels in FRTL-5 rat thyroid cells. Thyroid 7 789-794. (https://doi.org/10.1089/thy.1997.7.789)

Kelly WK, O'Connor OA, Krug LM, Chiao JH, Heaney M, Curley T, MacGregore-Cortelli B, Tong W, Secrist JP, Schwartz L, et al. 2005 Phase I study of an oral histone deacetylase inhibitor, suberoylanilide hydroxamic acid, in patients with advanced cancer. Journal of Clinical Oncology 23 3923-3931. (https://doi.org/10.1200/JCO.2005.14.167)

Kimura ET, Nikiforova MN, Zhu Z, Knauf JA, Nikiforov YE \& Fagin JA 2003 High prevalence of BRAF mutations in thyroid cancer: genetic evidence for constitutive activation of the RET/PTC-RAS-BRAF signaling pathway in papillary thyroid carcinoma. Cancer Research 63 1454-1457.

Knauf JA, Ma X, Smith EP, Zhang L, Mitsutake N, Liao XH, Refetoff S, Nikiforov YE \& Fagin JA 2005 Targeted expression of BRAFV600E in thyroid cells of transgenic mice results in papillary thyroid cancers that undergo dedifferentiation. Cancer Research 65 4238-4245. (https://doi.org/10.1158/0008-5472.CAN-05-0047)

Knauf JA, Sartor MA, Medvedovic M, Lundsmith E, Ryder M, Salzano M, Nikiforov YE, Giordano TJ, Ghossein RA \& Fagin JA 2011 Progression of BRAF-induced thyroid cancer is associated with epithelialmesenchymal transition requiring concomitant MAP kinase and TGFB signaling. Oncogene 30 3153-3162. (https://doi.org/10.1038/ onc.2011.44)
Kogai T \& Brent GA 2012 The sodium iodide symporter (NIS): regulation and approaches to targeting for cancer therapeutics. Pharmacology and Therapeutics 135 355-370. (https://doi.org/10.1016/j. pharmthera.2012.06.007)

Kogai T, Endo T, Saito T, Miyazaki A, Kawaguchi A \& Onaya T 1997 Regulation by thyroid-stimulating hormone of sodium/iodide symporter gene expression and protein levels in FRTL-5 cells. Endocrinology 138 2227-2232. (https://doi.org/10.1210/ endo.138.6.5189)

Kogai T, Sajid-Crockett S, Newmarch LS, Liu YY \& Brent GA 2008 Phosphoinositide-3-kinase inhibition induces sodium/iodide symporter expression in rat thyroid cells and human papillary thyroid cancer cells. Journal of Endocrinology 199 243-252. (https://doi. org/10.1677/JOE-08-0333)

Koumarianou P, de La Vieja A \& Santisteban P 2014 NIS is basolateraly sorted by AP-1A and AP-1B clathrin adaptors in MDCK cells. European Thyroid Journal 3 (Supplement 1) V-VI. (https://doi. org/10.1159/000365242)

Kussendrager KD \& van Hooijdonk ACM 2000 Lactoperoxidase: physicochemical properties, occurrence, mechanism of action and applications. British Journal of Nutrition 84 (Supplement 1) S19-S25. (https://doi.org/10.1017/s0007114500002208)

la Perle KMD, Kim DC, Hall NC, Bobbey A, Shen DH, Nagy RS, Wakely PE, Lehman A, Jarjoura D \& Jhiang SM 2013 Modulation of sodium/iodide symporter expression in the salivary gland. Thyroid 23 1029-1036. (https://doi.org/10.1089/thy.2012.0571)

Lacoste C, Hervé J, Nader MB, Santos A dos, Moniaux N, Valogne Y, Montjean R, Dorseuil O, Samuel D, Cassio D, et al. 2012 Iodide transporter NIS regulates cancer cell motility and invasiveness by interacting with the rho guanine nucleotide exchange factor LARG Cancer Research 72 5505-5515. (https://doi.org/10.1158/0008-5472. CAN-12-0516)

Lakshmanan A, Wojcicka A, Kotlarek M, Zhang X, Jazdzewski K \& Jhiang SM 2015a microRNA-339-5p modulates Na+/I- symportermediated radioiodide uptake. Endocrine-Related Cancer 22 11-21. (https://doi.org/10.1530/ERC-14-0439)

Lakshmanan A, Scarberry D, Green JA, Zhang X, Selmi-Ruby S \& Jhiang SM 2015 $b$ Modulation of thyroidal radioiodide uptake by oncological pipeline inhibitors and apigenin. Oncotarget 6 31792-31804. (https://doi.org/10.18632/oncotarget.5172)

Landa I, Ruiz-Llorente S, Montero-Conde C, Inglada-Pérez L, Schiavi F, Leskelä S, Pita G, Milne R, Maravall J, Ramos I, et al. 2009 The variant rs1867277 in FOXE1 gene confers thyroid cancer susceptibility through the recruitment of USF1/USF2 transcription factors. PLoS Genetics 5 e1000637. (https://doi.org/10.1371/journal.pgen.1000637)

Leoni SG, Kimura ET, Santisteban P \& De-La Vieja A 2011 Regulation of thyroid oxidative state by thioredoxin reductase has a crucial role in thyroid responses to iodide excess. Molecular Endocrinology 25 1924-1935. (https://doi.org/10.1210/me.2011-0038)

Leoni SG, Sastre-Perona A, De-La Vieja A \& Santisteban P 2016 Selenium increases thyroid-stimulating hormone-induced sodium/iodide symporter expression through thioredoxin/apurinic/apyrimidinic endonuclease 1-dependent regulation of paired box 8 binding activity. Antioxidants and Redox Signaling 24 855-866. (https://doi.org/10.1089/ ars.2014.6228)

Levy O, de La Vieja A, Ginter CS, Riedel C, Dai G \& Carrasco N 1998 $\mathrm{N}$-linked glycosylation of the thyroid $\mathrm{Na}+/ \mathrm{I}-$ symporter (NIS). Implications for its secondary structure model. Journal of Biological Chemistry 273 22657-22663. (https://doi.org/10.1074/jbc.273.35.22657)

Li L, Lv B, Chen B, Guan M, Sun Y, Li H, Zhang B, Ding C, He S \& Zeng Q 2015 Inhibition of miR-146b expression increases radioiodine-sensitivity in poorly differential thyroid carcinoma via positively regulating NIS expression. Biochemical and Biophysical Research Communications $462314-$ 321. (https://doi.org/10.1016/j.bbrc.2015.04.134)

Lin X, Ryu KY \& Jhiang SM 2004 Cloning of the 5'-flanking region of mouse sodium/iodide symporter and identification of a thyroid- 
specific and TSH-responsive enhancer. Thyroid 14 19-27. (https://doi. org/10.1089/105072504322783803)

Lints TJ, Parsons LM, Hartley L, Lyons I \& Harvey RP 1993 Nkx-2.5: a novel murine homeobox gene expressed in early heart progenitor cells and their myogenic descendants. Development 119 419-431. (https:// doi.org/10.1242/dev.119.2.419)

Liu D, Hu S, Hou P, Jiang D, Condouris S \& Xing M 2007a Suppression of BRAF/MEK/MAP kinase pathway restores expression of iodidemetabolizing genes in thyroid cells expressing the V600E BRAF mutant. Clinical Cancer Research 13 1341-1349. (https://doi. org/10.1158/1078-0432.CCR-06-1753)

Liu B, Hervé J, Bioulac-Sage P, Valogne Y, Roux J, Yilmaz F, Boisgard R, Guettier C, Calès P, Tavitian B, et al. 2007b Sodium iodide symporter is expressed at the preneoplastic stages of liver carcinogenesis and in human cholangiocarcinoma. Gastroenterology 132 1495-1503. (https:// doi.org/10.1053/j.gastro.2007.01.044)

Liu YY, Zhang X, Ringel MD \& Jhiang SM 2012 Modulation of sodium iodide symporter expression and function by LY294002, Akti-1/2 and rapamycin in thyroid cells. Endocrine-Related Cancer 19 291-304. (https://doi.org/10.1530/ERC-11-0288)

Luckett KA, Cracchiolo JR, Krishnamoorthy GP, Leandro-Garcia LJ, Nagarajah J, Saqcena M, Lester R, Im SY, Zhao Z, Lowe SW, et al. 2021 Co-inhibition of SMAD and MAPK signaling enhances 124I uptake in BRAF-mutant thyroid cancers. Endocrine-Related Cancer 28 391-402. (https://doi.org/10.1530/ERC-21-0017)

Martín M, Modenutti CP, Peyret V, Geysels RC, Darrouzet E, Pourcher T, Masini-Repiso AM, Martí MA, Carrasco N \& Nicola JP 2019 A carboxyterminal monoleucine-based motif participates in the basolateral targeting of the Na+/I- symporter. Endocrinology 160 156-168. (https:// doi.org/10.1210/en.2018-00603)

Martinez NJ, Ow MC, Barrasa MI, Hammell M, Sequerra R, DoucetteStamm L, Roth FP, Ambros VR \& Walhout AJM 2008 A C. elegans genome-scale microRNA network contains composite feedback motifs with high flux capacity. Genes and Development 22 2535-2549. (https://doi.org/10.1101/gad.1678608)

Massimino M, Tirrò E, Stella S, Frasca F, Vella V, Sciacca L, Pennisi MS, Vitale SR, Puma A, Romano C, et al. 2018 Effect of combined epigenetic treatments and ectopic NIS expression on undifferentiated thyroid cancer cells. Anticancer Research 38 6653-6662. (https://doi. org/10.21873/anticanres.13032)

Mazzaferri EL \& Young RL 1981 Papillary thyroid carcinoma: a 10 year foliow-up report of the impact of therapy in 576 patients. American Journal of Medicine 70 511-518. (https://doi.org/10.1016/00029343(81)90573-8)

Mitsutake N, Knauf JA, Mitsutake S, Mesa C, Zhang L \& Fagin JA 2005 Conditional BRAFV600E expression induces DNA synthesis, apoptosis, dedifferentiation, and chromosomal instability in thyroid PCCL3 cells. Cancer Research 65 2465-2473. (https://doi.org/10.1158/00085472.CAN-04-3314)

Mitsutake N, Miyagishi M, Mitsutake S, Akeno N, Mesa C, Knauf JA, Zhang L, Taira K \& Fagin JA 2006 BRAF mediates RET/PTC-induced mitogen-activated protein kinase activation in thyroid cells: functional support for requirement of the RET/PTC-RAS-BRAF pathway in papillary thyroid carcinogenesis. Endocrinology 147 1014-1019. (https://doi.org/10.1210/en.2005-0280)

Nagarajah J, Le M, Knauf JA, Ferrandino G, Montero-Conde C, Pillarsetty N, Bolaender A, Irwin C, Krishnamoorthy GP, Saqcena M, et al. 2016 Sustained ERK inhibition maximizes responses of BrafV600E thyroid cancers to radioiodine. Journal of Clinical Investigation 126 4119-4124. (https://doi.org/10.1172/JCI89067)

Neumann S, Schuchardt K, Reske A, Reske A, Emmrich P \& Paschke R 2004 Lack of correlation for sodium iodide symporter mRNA and protein expression and analysis of sodium iodide symporter promoter methylation in benign cold thyroid nodules. Thyroid 14 99-111. (https://doi.org/10.1089/105072504322880337)
Nicola JP, Nazar M, Mascanfroni ID, Pellizas CG \& Masini-Repiso AM 2010 NF-xB p65 subunit mediates lipopolysaccharide-induced $\mathrm{Na}+$ /Isymporter gene expression by involving functional interaction with the paired domain transcription factor Pax8. Molecular Endocrinology 24 1846-1862. (https://doi.org/10.1210/me.2010-0102)

Nilubol N, Merkel R, Yang L, Patel D, Reynolds JC, Sadowski SM, Neychev V \& Kebebew E 2017 A phase II trial of valproic acid in patients with advanced, radioiodine-resistant thyroid cancers of follicular cell origin. Clinical Endocrinology 86 128-133. (https://doi.org/10.1111/cen.13154)

Ohashi E, Kogai T, Kageehika H \& Brent GA 2009 Activation of the PI3 kinase pathway by retinoic acid mediates sodium/iodide symporter induction and iodide transport in MCF-7 breast cancer cells. Cancer Research 69 3443-3450. (https://doi.org/10.1158/0008-5472.CAN-08-3234)

Ohmori M, Endo T, Harii N \& Onaya T 1998 A novel thyroid transcription factor is essential for thyrotropin-induced up-regulation of $\mathrm{Na} / \mathrm{I}$ symporter gene expression. Molecular Endocrinology 12 727-736. (https://doi.org/10.1210/mend.12.5.0101)

Ohno M, Zannini M, Levy O, Carrasco N \& di Lauro R 1999 The paireddomain transcription factor Pax8 binds to the upstream enhancer of the rat sodium/iodide symporter gene and participates in both thyroid-specific and cyclic-AMP-dependent transcription. Molecular and Cellular Biology 19 2051-2060. (https://doi.org/10.1128/ MCB.19.3.2051)

Patel PN, Yu XM, Jaskula-Sztul R \& Chen H 2014 Hesperetin activates the Notch1 signaling cascade, causes apoptosis, and induces cellular differentiation in anaplastic thyroid cancer. Annals of Surgical Oncology 21 (Supplement 4) S497-S504. (https://doi.org/10.1245/s10434-013-3459-7)

Pei L \& Melmed S 1997 Isolation and characterization of a pituitary tumor-transforming gene (PTTG). Molecular Endocrinology 11 433-441. (https://doi.org/10.1210/mend.11.4.9911)

Pekary AE, Hershman JM \& Berg L 1998 Tumor necrosis factor, ceramide, transforming growth factor- $\beta 1$, and aging reduce $\mathrm{Na}+/ \mathrm{I}$ - symporter messenger ribonucleic acid levels in FRTL-5 cells. Endocrinology 139 703-712. (https://doi.org/10.1210/endo.139.2.5760)

Penha RCC, Buexm LA, Rodrigues FR, de Castro TP, Santos MCS, Fortunato RS, Carvalho DP, Cardoso-Weide LC \& Ferreira ACF 2018 NKX2.5 is expressed in papillary thyroid carcinomas and regulates differentiation in thyroid cells. BMC Cancer 18 498. (https://doi. org/10.1186/s12885-018-4399-1)

Plantinga TS, Heinhuis B, Gerrits D, Netea MG, Joosten LAB, Hermus ARMM, Oyen WJG, Schweppe RE, Haugen BR, Boerman OC, et al. 2014 mTOR inhibition promotes TTF1-dependent redifferentiation and restores iodine uptake in thyroid carcinoma cell lines. Journal of Clinical Endocrinology and Metabolism 99 E1368-E1375. (https://doi.org/10.1210/jc.2014-1171)

Portela A \& Esteller M 2010 Epigenetic modifications and human disease. Nature Biotechnology 28 1057-1068. (https://doi.org/10.1038/nbt.1685)

Portella G, Vitagliano D, Borselli C, Melillo RM, Salvatore D, Rothstein JL, Vecchio G, Fusco A \& Santoro M 1999 Human N-ras, TRK-Tl,smd RET/ PTC3. oncogenes, driven by a thyroglobulin promoter, differently affect the expression of differentiation markers and the proliferation of thyroid epithelial cells. Oncology Research 11 421-427.

Portulano C, Paroder-Belenitsky M \& Carrasco N 2014 The Na+/Isymporter (NIS): mechanism and medical impact. Endocrine Reviews 35 106-149. (https://doi.org/10.1210/er.2012-1036)

Provenzano MJ, Fitzgerald MP, Krager K \& Domann FE 2007 Increased iodine uptake in thyroid carcinoma after treatment with sodium butyrate and decitabine (5-Aza-dC). Otolaryngology: Head and Neck Surgery 137 722-728. (https://doi.org/10.1016/j.otohns.2007.07.030)

Puppin C, D’Aurizio F, D'Elia A v., Cesaratto L, Tell G, Russo D, Filetti S, Ferretti E, Tosi E, Mattei T, et al. 2005 Effects of histone acetylation on NIS promoter and expression of thyroid-specific transcription factors. Endocrinology 146 3967-3974. (https://doi.org/10.1210/en.2005-0128)

Ramírez-Moya J \& Santisteban P 2021 A positive feedback loop between DICER1 and differentiation transcription factors is important for (c) 2021 Society for Endocrinology Published by Bioscientifica Ltd. Printed in Great Britain 
thyroid tumorigenesis. Thyroid 31 912-921. (https://doi.org/10.1089/ thy.2020.0297)

Rathod M, Chatterjee S, Dutta S, Kalraiya R, Bhattacharyya D \& De A 2019 Mannose glycosylation is an integral step for NIS localization and function in human breast cancer cells. Journal of Cell Science 132 jcs232058. (https://doi.org/10.1242/jcs.232058)

Ravera S, Reyna-Neyra A, Ferrandino G, Amzel LM \& Carrasco N 2017 The sodium/iodide symporter (NIS): molecular physiology and preclinical and clinical applications. Annual Review of Physiology 79 261-289. (https://doi.org/10.1146/annurev-physiol-022516-034125)

Read ML, Lewy GD, Fong JCW, Sharma N, Seed RI, Smith VE, Gentilin E, Warfield A, Eggo MC, Knauf JA, et al. 2011 Proto-oncogene PBF/ PTTG1IP regulates thyroid cell growth and represses radioiodide treatment. Cancer Research 71 6153-6164. (https://doi. org/10.1158/0008-5472.CAN-11-0720)

Read M, Brookes K, Thornton C, Fletcher A, Alshahrani M, Khan R, Nieto H, Borges de Souza P, Webster J, Alderwick L, et al. 2020 New mechanisms of radioiodide uptake revealed via a novel high throughput drug screening approach in thyroid cancer. bioRxiv [epub]. (https://doi.org/10.1101/2020.07.21.213967)

Riedel C, Levy O \& Carrasco N 2001 Post-transcriptional regulation of the sodium/iodide symporter by thyrotropin. Journal of Biological Chemistry 276 21458-21463. (https://doi.org/10.1074/jbc.M100561200)

Riesco-Eizaguirre G \& Santisteban P 2016 ENDOCRINE TUMOURS: Advances in the molecular pathogenesis of thyroid cancer: lessons from the cancer genome. European Journal of Endocrinology 175 R203-R217. (https://doi.org/10.1530/EJE-16-0202)

Riesco-Eizaguirre G, Gutiérrez-Martínez P, García-Cabezas MA, Nistal M \& Santisteban P 2006 The oncogene BRAFV600E is associated with a high risk of recurrence and less differentiated papillary thyroid carcinoma due to the impairment of $\mathrm{Na}+/ \mathrm{I}-$ targeting to the membrane. Endocrine-Related Cancer 13 257-269. (https://doi. org/10.1677/erc.1.01119)

Riesco-Eizaguirre G, Rodríguez I, de La Vieja A, Costamagna E, Carrasco N, Nistal M \& Santisteban P 2009 The BRAFV600E oncogene induces transforming growth factor $\beta$ secretion leading to sodium iodide symporter repression and increased malignancy in thyroid cancer. Cancer Research 69 8317-8325. (https://doi.org/10.1158/0008-5472. CAN-09-1248)

Riesco-Eizaguirre G, Leoni SG, Mendiola M, Estevez-Cebrero MA, Gallego MI, Redondo A, Hardisson D, Santisteban P \& de la Vieja A 2014 NIS mediates iodide uptake in the female reproductive tract and is a poor prognostic factor in ovarian cancer. Journal of Clinical Endocrinology and Metabolism 99 E1199-E1208. (https://doi. org/10.1210/jc.2013-4249)

Riesco-Eizaguirre G, Wert-Lamas L, Perales-Paton J, Sastre-Perona A, Fernandez LP \& Santisteban P 2015 The miR-146b-3p/PAX8/NIS regulatory circuit modulates the differentiation phenotype and function of thyroid cells during carcinogenesis. Cancer Research $\mathbf{7 5}$ 4119-4130. (https://doi.org/10.1158/0008-5472.CAN-14-3547)

Russo D, Durante C, Bulotta S, Puppin C, Puxeddu E, Filetti S \& Damante G 2013 Targeting histone deacetylase in thyroid cancer. Expert Opinion on Therapeutic Targets 17 179-193. (https://doi.org/10.15 17/14728222.2013.740013)

Saji M \& Kohn LD 1991 Insulin and insulin-like growth factor-I inhibit thyrotropin-increased iodide transport in serum-depleted FRTL-5 rat thyroid cells: modulation of adenosine $3^{\prime}, 5^{\prime}$-monophosphate signal action. Endocrinology 128 1136-1143. (https://doi.org/10.1210/endo128-2-1136)

Schaffner W 2015 Enhancers, enhancers - from their discovery to today's universe of transcription enhancers. Biological Chemistry 396 311-327. (https://doi.org/10.1515/hsz-2014-0303)

Schmitt TL, Espinoza CR \& Loos U 2002 Characterization of a thyroidspecific and cyclic adenosine monophosphate-responsive enhancer far upstream from the human sodium iodide symporter gene. Thyroid $\mathbf{1 2}$ 273-279. (https://doi.org/10.1089/10507250252949388)
Schmutzler C, Winzer R, Meissner-Weigl J \& Köhrle J 1997 Retinoic acid increases sodium/lodide symporter mRNA levels in human thyroid cancer cell lines and suppresses expression of functional symporter in nontransformed FRTL-5 rat thyroid cells. Biochemical and Biophysical Research Communications 240 832-838. (https://doi.org/10.1006/ bbrc.1997.7715)

Schmutzler C, Schmitt TL, Glaser F, Loos U \& Köhrle J 2002 The promoter of the human sodium/iodide-symporter gene responds to retinoic acid. Molecular and Cellular Endocrinology 189 145-155. (https://doi. org/10.1016/S0303-7207(01)00735-3)

Seissler J, Wagner S, Schott M, Lettmann M, Feldkamp J, Scherbaum WA \& Morgenthaler NG 2000 Low frequency of autoantibodies to the human Na+/I- symporter in patients with autoimmune thyroid disease. Journal of Clinical Endocrinology and Metabolism 85 4630-4634. (https://doi.org/10.1210/jc.85.12.4630)

Shiozaki A, Ariyoshi Y, Iitaka D, Kosuga T, Shimizu H, Kudou M, Konishi T, Shoda K, Arita T, Konishi H, et al. 2019 Functional analysis and clinical significance of sodium iodide symporter expression in gastric cancer. Gastric Cancer 22 473-485. (https://doi.org/10.1007/s10120018-0874-2)

Smith JA, Fan CY, Zou C, Bodenner D \& Kokoska MS 2007 Methylation status of genes in papillary thyroid carcinoma. Archives of Otolaryngology: Head and Neck Surgery 133 1006-1011. (https://doi org/10.1001/archotol.133.10.1006)

Smith VE, Read ML, Turnell AS, Watkins RJ, Watkinson JC, Lewy GD, Fong JCW, James SR, Eggo MC, Boelaert K, et al. 2009 A novel mechanism of sodium iodide symporter repression in differentiated thyroid cancer. Journal of Cell Science 122 3393-3402. (https://doi. org/10.1242/jcs.045427)

Smith VE, Franklyn JA \& McCabe CJ 2011 Expression and function of the novel proto-oncogene PBF in thyroid cancer: a new target for augmenting radioiodine uptake. Journal of Endocrinology 210 157-163. (https://doi.org/10.1530/JOE-11-0064)

Soares P, Trovisco V, Rocha AS, Lima J, Castro P, Preto A, Máximo V, Botelho T, Seruca R \& Sobrinho-Simões M 2003 BRAF mutations and RET/PTC rearrangements are alternative events in the etiopathogenesis of PTC. Oncogene 22 4578-4580. (https://doi. org/10.1038/sj.onc.1206706)

Spitzweg C \& Morris JC 2000 The immune response to the iodide transporter. Endocrinology and Metabolism Clinics of North America 29 389-398, viii. (https://doi.org/10.1016/S0889-8529(05)70138-9)

Spitzweg C, Joba W, Morris JC \& Heufelder AE 1999 Regulation of sodium iodide symporter gene expression in FRTL-5 rat thyroid cells. Thyroid 9 821-830. (https://doi.org/10.1089/thy.1999.9.821)

Stephen JK, Chitale D, Narra V, Chen KM, Sawhney R \& Worsham MJ 2011 DNA methylation in thyroid tumorigenesis. Cancers 3 1732-1743. (https://doi.org/10.3390/cancers3021732)

Stratford AL, Boelaert K, Tannahill LA, Kim DS, Warfield A, Eggo MC, Gittoes NJL, Young LS, Franklyn JA \& McCabe CJ 2005 Pituitary tumor transforming gene binding factor: a novel transforming gene in thyroid tumorigenesis. Journal of Clinical Endocrinology and Metabolism 90 4341-4349. (https://doi.org/10.1210/jc.2005-0523)

Taki K, Kogai T, Kanamoto Y, Hershman JM \& Brent GA 2002 A thyroidspecific far-upstream enhancer in the human sodium/iodide symporter gene requires Pax- 8 binding and cyclic adenosine 3',5'-monophosphate response element-like sequence binding proteins for full activity and is differentially regulated in normal and thyroid cancer cells. Molecular Endocrinology 16 2266-2282. (https:// doi.org/10.1210/me.2002-0109)

Tang Y, Meng X, Yu X, Shang H, Chen S, Liao L \& Dong J 2020 Inhibition of microRNA-875-5p promotes radioiodine uptake in poorly differentiated thyroid carcinoma cells by upregulating sodium-iodide symporter. Journal of Endocrinological Investigation 43 439-450. (https://doi.org/10.1007/s40618-019-01125-3)

Tavares C, Eloy C, Melo M, Gaspar da Rocha A, Pestana A, Batista R, Bueno Ferreira L, Rios E, Sobrinho Simões M \& Soares P 2018 mTOR pathway https://erc bioscientifica com

https://doi.org/10.1530/ERC-21-0217
C) 2021 Society for Endocrinology Published by Bioscientifica Ltd. Printed in Great Britain 
in papillary thyroid carcinoma: different contributions of mTORC1 and mTORC2 complexes for tumor behavior and SLC5A5 mRNA expression. International Journal of Molecular Sciences 19 1448. (https:// doi.org/10.3390/ijms19051448)

Tazebay UH, Wapnir IL, Levy O, Dohan O, Zuckier LS, Zhao QH, Deng HF, Amenta PS, Fineberg S, Pestell RG, et al. 2000 The mammary gland iodide transporter is expressed during lactation and in breast cancer. Nature Medicine 6 871-878. (https://doi.org/10.1038/78630)

Tonacchera M, Agretti P, Ceccarini G, Lenza R, Refetoff S, Santini F, Pinchera A, Chiovato L \& Vitti P 2001 Autoantibodies from patients with autoimmune thyroid disease do not interfere with the activity of the human iodide symporter gene stably transfected in $\mathrm{CHO}$ cells. European Journal of Endocrinology 144 611-618. (https://doi. org/10.1530/eje.0.1440611)

Tuncel M, Aydin D, Yaman E, Tazebay UH, Güç D, Doğan AL, Taşbasan B \& Uğur O 2007 The comparative effects of gene modulators on thyroidspecific genes and radioiodine uptake. Cancer Biotherapy and Radiopharmaceuticals 22 443-449. (https://doi.org/10.1089/ cbr.2006.319.A)

Vadysirisack DD, Chen ESW, Zhang Z, Tsai MD, Chang GD \& Jhiang SM 2007 Identification of in vivo phosphorylation sites and their functional significance in the sodium iodide symporter. Journal of Biological Chemistry 282 36820-36828. (https://doi.org/10.1074/jbc. M706817200)

Vasko V, Espinosa AV v., Scouten W, He H, Auer H, Liyanarachchi S, Larin A, Savchenko V, Francis GL, de La Chapelle A, et al. 2007 Gene expression and functional evidence of epithelial-to-mesenchymal transition in papillary thyroid carcinoma invasion. PNAS $\mathbf{1 0 4}$ 2803-2808. (https://doi.org/10.1073/pnas.0610733104)

Venkataraman GM, Yatin M, Marcinek R \& Ain KB 1999 Restoration of iodide uptake in dedifferentiated thyroid carcinoma: relationship to human Na+/I- symporter gene methylation status. Journal of Clinical Endocrinology and Metabolism 84 2449-2457. (https://doi.org/10.1210/ jcem.84.7.5815)

Verdone L, Agricola E, Caserta M \& Di Mauro E 2006 Histone acetylation in gene regulation. Briefings in Functional Genomics and Proteomics 5 209-221. (https://doi.org/10.1093/bfgp/ello28)

Wächter S, Damanakis AI, Elxnat M, Roth S, Wunderlich A, Verburg FA, Fellinger SA, Bartsch DK \& di Fazio P 2018 Epigenetic modifications in thyroid cancer cells restore NIS and radio-iodine uptake and promote cell death. Journal of Clinical Medicine 7 61. (https://doi.org/10.3390/ jcm7040061)

Wang J, Knauf JA, Basu S, Puxeddu E, Kuroda H, Santoro M, Fusco A \& Fagin JA 2003 Conditional expression of RET/PTC induces a weak oncogenic drive in thyroid PCCL3 cells and inhibits thyrotropin action at multiple levels. Molecular Endocrinology 17 1425-1436. (https://doi.org/10.1210/me.2003-0041)

Wapnir IL, van de Rijn M, Nowels K, Amenta PS, Walton K, Montgomery K, Greco RS, Dohán O \& Carrasco N 2003 Immunohistochemical profile of the sodium/iodide symporter in thyroid, breast, and other carcinomas using high density tissue microarrays and conventional sections. Journal of Clinical Endocrinology and Metabolism 88 1880-1888. (https://doi.org/10.1210/jc.2002021544)

Wapnir IL, Goris M, Yudd A, Dohan O, Adelman D, Nowels K \& Carrasco N 2004 The Na+/I- symporter mediates iodide uptake in breast cancer metastases and can be selectively down-regulated in the thyroid. Clinical Cancer Research 10 4294-4302. (https://doi. org/10.1158/1078-0432.CCR-04-0074)

Weiss SJ, Philp NJ, Ambesi-Impiombato FS \& Grollman EF 1984 Thyrotropin-stimulated iodide transport mediated by adenosine 3',5'-monophosphate and dependent on protein synthesis. Endocrinology 114 1099-1107. (https://doi.org/10.1210/endo-114-41099)

Wolff J 1964 Transport of iodide and other anions in the thyroid gland. Physiological Reviews 44 45-90. (https://doi.org/10.1152/ physrev.1964.44.1.45)

Wolff J \& Chaikoff IL 1948 The inhibitory action of excessive iodide upon the synthesis of diiodotyrosine and of thyroxine in the thyroid gland of the normal rat. Endocrinology 43 174-179. (https://doi.org/10.1210/ endo-43-3-174)

Wolff J \& Chaikoff IL 1949 The temporary nature of the inhibitory action of excess iodine on organic iodine synthesis in the normal thyroid. Endocrinology 45 504-513. (https://doi.org/10.1210/endo-45-5-504)

Woyach JA, Kloos RT, Ringel MD, Arbogast D, Collamore M, Zwiebel JA, Grever M, Villalona-Calero M \& Shah MH 2009 Lack of therapeutic effect of the histone deacetylase inhibitor vorinostat in patients with metastatic radioiodine-refractory thyroid carcinoma. Journal of Clinical Endocrinology and Metabolism 94 164-170. (https://doi.org/10.1210/ jc.2008-1631)

Xiao X, Ning L \& Chen H 2009 Notch1 mediates growth suppression of papillary and follicular thyroid cancer cells by histone deacetylase inhibitors. Molecular Cancer Therapeutics 8 350-356. (https://doi. org/10.1158/1535-7163.MCT-08-0585)

Xing M 2007 Gene methylation in thyroid tumorigenesis. Endocrinology 148 948-953. (https://doi.org/10.1210/en.2006-0927)

Xing M 2010 Genetic alterations in the phosphatidylinositol-3 kinase/Akt pathway in thyroid cancer. Thyroid 20 697-706. (https://doi. org/10.1089/thy.2010.1646)

Xu J \& Hershman JM 2006 Histone deacetylase inhibitor depsipeptide represses nicotinamide $\mathrm{N}$-methyltransferase and hepatocyte nuclear factor- $1 \beta$ gene expression in human papillary thyroid cancer cells. Thyroid 16 151-160. (https://doi.org/10.1089/thy.2006.16.151)

Xu J, Kogai T, Brent GA \& Hershman JM 2002 A GC box in the human sodium iodide symporter gene promoter is essential for full activity. Thyroid 12 107-114. (https://doi.org/10.1089/105072502753522338)

Yu X, Shen H, Liu L, Lin L, Gao M \& Wang S 2012 Changes of sodium iodide symporter regulated by IGF-I and TGF- $\beta 1$ in mammary gland cells from lactating mice at different iodine levels. Biological Trace Element Research 146 73-78. (https://doi.org/10.1007/s12011-011-9227-2)

Yu XM, Jaskula-Sztul R, Ahmed K, Harrison AD, Kunnimalaiyaan M \& Chen H 2013 Resveratrol induces differentiation markers expression in anaplastic thyroid carcinoma via activation of Notch1 signaling and suppresses cell growth. Molecular Cancer Therapeutics 12 1276-1287. (https://doi.org/10.1158/1535-7163.MCT-12-0841)

Zaballos MA, Garcia B \& Santisteban P 2008 G $\beta \gamma$ dimers released in response to thyrotropin activate phosphoinositide 3-kinase and regulate gene expression in thyroid cells. Molecular Endocrinology 22 1183-1199. (https://doi.org/10.1210/me.2007-0093)

Zafon C, Gil J, Pérez-González B \& Jordà M 2019 DNA methylation in thyroid cancer. Endocrine-Related Cancer 26 R415-R439. (https://doi. org/10.1530/ERC-19-0093)

Received in final form 5 August 2021

Accepted 13 August 2021

Accepted Manuscript published online 13 August 2021 https://erc.bioscientifica.com https://doi.org/10.1530/ERC-21-0217 (c) 2021 Society for Endocrinology Published by Bioscientifica Ltd. Printed in Great Britain 